\title{
Does Foreign Information Predict the Returns of Multinational Firms Worldwide?
}

\author{
Christian Finke and Florian Weigert*
}

This Version: October 2016

\begin{abstract}
We investigate whether value-relevant foreign information only gradually dilutes into stock prices of multinational firms worldwide. Using an international sample of firms from 22 developed countries, we find that a portfolio strategy based on firms' foreign sales information yields future returns of more than $10 \%$ p.a. globally. The return spread due to foreign information is substantial across different geographical regions and cannot be explained by traditional risk factors, firm characteristics, and industry momentum. Our results are in line with limited attention of investors to foreign information being the main driver of this effect worldwide.
\end{abstract}

Keywords: Foreign information, return predictability, limited attention

JEL Classification Numbers: G12, G14, G15

\footnotetext{
* Christian Finke is from the University of St. Gallen, Swiss Institute of Banking and Finance, Rosenbergstrasse 52, 9000 St. Gallen, Switzerland. Email: christian.finke@student.unisg.ch. Florian Weigert is from the University of St. Gallen, Swiss Institute of Banking and Finance, Rosenbergstrasse 52, 9000 St. Gallen, Switzerland. Email: florian.weigert@unisg.ch. Tel: +41-71-224-7014. We thank Zeno Adams, Alexander Gruber, Andreas Grüner, Alexander Hillert, Heiko Jacobs, Christoph Meinerding, Michael Ungeheuer, Daniel Urban, and the participants at the Swiss Finance Meeting 2016, the German Finance Meeting 2016, and the research seminar at the University of St.Gallen for their helpful comments and constructive suggestions. All errors are our own.
} 


\title{
Does Foreign Information Predict the Returns of Multinational Firms Worldwide?
}

\author{
This Version: October 2016
}

\begin{abstract}
We investigate whether value-relevant foreign information only gradually dilutes into stock prices of multinational firms worldwide. Using an international sample of firms from 22 developed countries, we find that a portfolio strategy based on firms' foreign sales information yields future returns of more than $10 \%$ p.a. globally. The return spread due to foreign information is substantial across different geographical regions and cannot be explained by traditional risk factors, firm characteristics, and industry momentum. Our results are in line with limited attention of investors to foreign information being the main driver of this effect worldwide.
\end{abstract}

Keywords: Foreign information, return predictability, limited attention

JEL Classification Numbers: G12, G14, G15 


\section{Introduction}

The continuing globalization over the past decades has led to a liberalization of international trade, capital flows and a more integrated global economy. As a result, there is an increasing number of internationally diversified firms that sell their products and services in multiple countries. For example, Denis et al. (2002) report that the share of globally diversified U.S. firms has increased from $29 \%$ to $45 \%$ between 1984 and 1997. Also the fraction of total sales coming from foreign markets has increased from $21 \%$ to $29 \%$ during this time span.

A multinational firm, which generates sales in multiple geographic regions, is exposed to unexpected economic shocks from its corresponding geographic segments. Specifically, a positive (negative) shock to a foreign country's industry segment - where the firm operates - is likely to increase (decrease) the multinational corporation's future financial performance. At the same time, it is reasonable to assume that investors are challenged with investments in these firms because they are limited in their time and ability to process complicated but relevant information (e.g., Grossman and Stiglitz, 1980; Merton, 1987; Hong and Stein, 2007; Duffie, 2010). These restrictions in investors' attention have the potential to induce market inefficiencies in the form of slow, rather than immediate, incorporation of new information into stock prices. In line with this idea, Huang (2015) finds that a portfolio strategy based on foreign sales information of multinational firms in the USA generates abnormal returns of $9.6 \%$ p.a. and that this spread is not due to conventional risk factors, firm characteristics, or industry momentum. ${ }^{1}$

In this paper we extend the study of Huang (2015) to a worldwide scale and use a sample of multinational firms from 22 countries in our empirical analysis. This broader international sample enables us to investigate whether the foreign information predictability effect is a specific feature of the U.S.

\footnotetext{
${ }^{1}$ Similar results are found by Nguyen (2012). He documents that a simple portfolio strategy exploiting foreign information yields a risk-adjusted return of 135 basis points per month or $16.2 \%$ per annum in the United States.
} 
market or extends to other markets globally. Moreover, it allows us to study the relationship between investor characteristics as well as macroeconomic variables and the strength of the predictability effect at the individual country level.

To proxy for a firm's foreign information, we use the sales-weighted average of industry-level returns in the relevant foreign countries. As an example, consider a firm that is located in the United Kingdom (U.K.) and operates in the pharma sector with 50\% of its sales located in the U.K., $30 \%$ in the USA, and $20 \%$ in Japan. The foreign info proxy (Foreign_Info) at month $t$ is computed as 0.3 times the pharma-industry return of the USA at month $t$ plus 0.2 times the pharma-industry return of Japan at month $t$.

We show that Foreign_Info has significant predictive power for multinationals' future stock returns on a global scale and across different geographical subsamples. In the pooled worldwide sample including U.S. stocks (excluding U.S. stocks) from June 2001 to December 2013, stocks with the highest Foreign_Info in month $t-1$ outperform stocks with the lowest Foreign_Info on average by $0.85 \%(0.63 \%)$ in month $t$. This outperformance translates into a large annual return spread of $10.20 \%(7.56 \%)$. Furthermore, we find that the return spread due to Foreign_Info (the Foreign_Info effect) is positive across the different geographical subsamples Asia-Pacific, Europe, and North America and amounts to $9.72 \%$ p.a., $4.56 \%$ p.a., and $9.72 \%$ p.a., respectively. ${ }^{2}$

Is the Foreign_Info effect explained by a stock's risk exposure to traditional asset pricing factor models and/or other firm characteristics? No. Our results indicate that the returns of a worldwide portfolio strategy going long in stocks with high Foreign_Info and going short in stocks with low Foreign_Info risk-adjusted by global versions of the Carhart (1997) four-factor model and the Fama and French (2015a)

\footnotetext{
${ }^{2}$ The return spread is statistically significant at the 5\% significance level for Asia-Pacific and North America. The spread is not statistically significant at the $10 \%$ significance level for Europe.
} 
five-factor model - still earn statistically significant alphas of $0.89 \%$ and $0.69 \%$ per month $(10.68 \%$ and $8.28 \%$ per annum). ${ }^{3}$ In addition, Foreign_Info shows a robust positive and statistically significant impact on future returns in multivariate Fama-MacBeth regressions when we control for additional firm characteristics, such as market beta (Sharpe, 1964; Lintner, 1965), size (Banz, 1981), book-to-market (Basu, 1983), momentum (Jegadeesh and Titman, 1993), short term reversal (Jegadeesh, 1990; Lo and McKinley, 1990), turnover (Rouwenhorst, 1999; Ibbotson et al., 2013), and idiosyncratic volatility (Ang et al., 2006; Ang et al., 2009). We also show that Foreign_Info predicts returns up to three months into the future and that the effect is robust when we use firm-individual Carhart (1997) alphas (instead of excess returns) as the dependent variable in our regression tests.

A potential concern is that the Foreign_Info effect is driven by industry momentum as shown in Moskowitz and Grinblatt (1999) and Nijman et al. (2004). We investigate the impact of foreign information on future risk-adjusted returns when explicitly controlling for lagged domestic industry returns in portfolio double sorts. Our results indicate that the positive and statistically significant impact of Foreign_Info on future returns remains large when controlling for industry momentum. Hence, industry momentum is unable to explain the cross-sectional variation in future stock returns due to Foreign_Info.

Having established a profound positive link between Foreign_Info and future stock returns on a global scale, we investigate the degree of comovement of the country-specific return spreads due to Foreign_Info across all 22 individual countries in our sample. We find that return spreads due to Foreign_Info across countries display a positive but only modest average correlation of 0.12 among each

\footnotetext{
${ }^{3}$ We obtain similar results if we adjust returns by global versions of the CAPM one-factor model or the Fama and French (1993) three-factor model. However, our results are only indicative, as we do not take into account any trading costs when forming the portfolio strategy.
} 
other. Furthermore, we show that the global return spread due to Foreign_Info has only weak explanatory power to explain the time-series variation of country-individual Foreign_Info return spreads. Hence, the time-series variation of the Foreign_Info effect is largely driven by time-varying country-specific factors. $^{4}$

We then shed light on possible drivers of this effect. Our main hypothesis is that (countryspecific) inattention of investors to foreign information delays the incorporation of news into stock prices and increases the return predictability of multinationals' future returns. Our empirical tests support this notion and reveal the following results:

(i) The Foreign_Info effect is particularly strong for small stocks, stocks with low analyst coverage, stocks that are held from a low number of institutional investors, and stocks with high idiosyncratic volatility. This result is in line with Nguyen (2012) and Huang (2015) for the USA and supports the idea that predictability is strongest among firms that generally receive less investor attention and stocks that are difficult to arbitrage. Furthermore, we find that differences in common language between the multinational firm's resident country and its sales countries contribute significantly to the gradual diffusion of foreign information. This finding suggests that investors face greater challenges in processing information from countries with a different language than their home country.

(ii) The country-specific return spread due to Foreign_Info is significantly larger following months in which domestic investors have displayed low attention to value-relevant foreign financial information. We use search frequency statistics from Google Trends as previously employed in Da et al. (2011) and Da et al. (2015) as a direct measure for investor attention. Precisely, we show that the

\footnotetext{
${ }^{4}$ A principal component analysis on the matrix of return spreads due to Foreign_Info of the 22 individual countries in our sample shows that only $19.22 \%(27.06 \%, 33.92 \%)$ of the overall variance can be explained by the first (two, three) principal components.
} 
abnormal search frequency of investors in country $i$ with regard to foreign stock markets in month $t-1$ has a negative impact on the magnitude of country $i$ 's return spread due to Foreign_Info in month $t$. Hence, we uncover a direct relationship between investors' attention to foreign information and the magnitude of the Foreign_Info effect across individual countries.

(iii) The Foreign_Info effect is particularly large in countries characterized by strong domestic bias and segmented equity markets. Hence, diffusion of foreign information into domestic stock prices occurs particularly slowly in countries where investors under-proportionally contribute their wealth into foreign assets and where equity markets are less integrated into the global financial system.

Our study is related to a broader literature on firm-level return predictability due to gradual information diffusion across geographic segments, firms, and time. Hou (2007) argues that the slow diffusion of industry information is a leading cause of the lead-lag effect in stock returns. Cohen and Frazzini (2008) and Menzly and Ozbas (2010) find that stock prices do not promptly incorporate news about economically related firms which generates return predictability across assets. Rizzova (2013) explores the interactions between international trade and stock markets and finds that stock market returns of trading partners do forecast trade flows and future returns. Cohen and Lou (2012) document return predictability from the set of single industry firms to more complicated peers such as conglomerates and Cao et al. (2015) show that stock returns of strategic alliance partners predict each other. Smajlbegovic (2016) and Addoum et al. (2015) find that U.S. state level economic activity measures predict fundamentals and returns of U.S. firms that are economically exposed to these states. Finally, Nguyen (2012) and Huang (2015) investigate the hypothesis that value-relevant foreign information slowly diffuses into the stock prices of U.S. multinational firms. They find that stock prices do not promptly incorporate information regarding changes in foreign market conditions and that a simple portfolio 
strategy that exploits geographic information yields high abnormal risk-adjusted returns. Our paper enhances the existing literature by documenting that foreign information is globally priced into stock prices with a considerable delay and limited attention of investors is likely to be the main driver of this obstacle worldwide.

We proceed as follows. In Section 2, we summarize the international stock market data and explain the methodology of the empirical analysis. Section 3 shows that stocks with high Foreign_Info earn higher future (risk-adjusted) returns than stocks with low Foreign_Info worldwide and across geographical subsamples. In Section 4, we analyze the comovement of the return spread due to Foreign_Info across individual countries. Section 5 sheds light on drivers of the Foreign_Info effect and Section 6 concludes.

\section{Data and Methodology}

\subsection{Data}

The dataset employed in this paper covers 22 developed markets according to the MSCI classification as of December 2013 and is compiled from different sources: geographical segment data and accounting information for firms located in the United States is from Compustat. Price, volume and return data for U.S. firms are from the Center for Research in Security Prices (CRSP). We restrict our sample to common equity (share code 10 or 11 in CRSP) listed on the NYSE, AMEX or NASDAQ. Our data sources for firms located outside the United States are Thomson Reuters Datastream and Worldscope. Total returns, prices, market values and trading volumes for all non-U.S. firms are obtained from Datastream. Geographical segment information and accounting data are from Worldscope. Finally, institutional ownership data and analyst coverage for all firms in the sample are obtained from Lionshares and Thomson Reuters I/B/E/S, respectively. The sample period is from June 2001 to December 2013 with 
a total of 151 months. We choose this period because geographic segment information from Worldscope for non-U.S. firms is scarce before 2000.

The Statement of Financial Accounting Standards (SFAS) No. 131 requires public business enterprises located in the United Sates to disclose geographical segment information in their annual financial statements. ${ }^{5}$ Similar regulations exist for international firms according to the International Financial Reporting Standard (IFRS) No. 8. According to these standards, firms are required to report financial information for individual geographic segments, which comprise $10 \%$ or more of total sales, profit or loss, or assets. Firms are required to report measures of profit and loss, such as sales, operating income and assets for each geographic segment. However, there are potential limitations with the reported geographical segment information. In particular, firms are allowed to aggregate multiple geographic areas into one reported geographic segment. For example, a U.S. multinational firm with sales in Germany, France, and Italy, might aggregate these countries into one segment Europe. ${ }^{6}$

We restrict our dataset to stocks classified as common equity listed on a regular stock exchange in their respective home country. ${ }^{7}$ If a firm has issued multiple share classes, we use the share class identified by Datastream as the major issue. ${ }^{8}$ As for U.S. firms, all stocks are required to be headquartered in their home country. Since we are primarily interested in stock price responses to foreign information, we exclude firms with $100 \%$ sales in the domestic market. Finally, we exclude very small firms with low price levels from our sample in order to avoid potential micro-structure effects such as bid-ask-bounce.

\footnotetext{
${ }^{5}$ SFAS 131 is effective for financial statements for periods beginning after December 15, 1997.

${ }^{6} \mathrm{We}$ address this potential issue in our robustness checks in Section 3.4. Specifically, we report the results of asset pricing tests when excluding all firms that do not exclusively report individual countries in their geographical segments. Our key results remain unchanged.

${ }^{7}$ Following the recommendation of Ince and Porter (2006) and Griffin et al. (2010), we screen the name of each security for labels which indicate that a security is not common equity.

${ }^{8}$ Datastream will usually choose the major security based on a combination of factors, such as liquidity and market capitalization.
} 
Hence, for each country and month, we exclude stocks that fall into the $5 \%$ percentile according to their market capitalization or price level at the end of the previous month. As indicated in Ince and Porter (2006), these stocks are particularly known to be prone to potential data errors. We also apply the screenings suggested by Ince and Porter (2006) to the total returns from Datastream. ${ }^{9}$ To mitigate further concerns with respect to illiquidity and infrequent trading of stocks, we require firms to trade on every day of month $t-1$ to be included in our empirical analysis in month $t$. As common in the international asset pricing literature, all stock returns are denominated in USD (e.g., Griffin, 2002; Fama and French, 2012). As in Fama and French (2012), we use the one-month U.S. T-bill rate for the USA and the remaining countries to calculate monthly excess returns. ${ }^{10}$

\subsection{Foreign Information}

The main variable of interest in this paper is a firm's "foreign information", which we refer to as Foreign_Info. To compute this measure, we first need an exposure of each multinational firm to a specific country or region. Second, we need to construct a measure for the economically relevant information from that country or region. ${ }^{11}$ To do so, we compute Foreign_Info as the sales-weighted sum of corresponding industry returns in relevant foreign countries:

$$
\text { Foreign_Info } o_{i, j, t}=\sum_{c \neq \text { Home }} f_{i, t}^{c} \cdot R_{j, t}^{c}
$$

\footnotetext{
${ }^{9}$ In particular, we delete all zero return observations starting from the end of the sample up until the first non-zero return. In addition, we set all returns with an extreme reversal over two consecutive months to missing, i.e. if $R_{t}>300 \%$ or $R_{t+1}>300 \%$ and $\left(1+R_{t}\right)\left(1+R_{t+1}\right)-1<50 \%$, we set both observations to missing.

${ }^{10}$ Our results are stable if we use local currency returns and work with raw returns instead of excess returns.

${ }^{11}$ A practical issue when working with geographical segment information from Compustat or Worldscope is that the geographical segment labels are not standardized. For example, a geographic segment can be labeled as "United Kingdom", "U.K.", "UK", "Great Britain", or "England", etc. Therefore, we manually go through all unique segment labels in the sample and assign one standardized label to each different geographic area. We come up with a total number of 59 geographic areas in the standardized geographic segments.
} 
where Foreign_Info ${ }_{i, j, t}$ denotes the foreign information proxy for firm $i$ belonging to industry $j$ during month $t, f_{i, t}^{c}$ denotes the fraction of sales from country c (note that $\sum_{c \neq \text { Home }} f_{i, t}^{c} \neq 1$ ), and $R_{j, t}^{c}$ denotes industry $j$ 's return in country $c$ during month $t .{ }^{12}$ For example, a firm that is located in the U.K. and operates in the pharma sector with $50 \%$ of its sales located in the U.K., $30 \%$ in the USA, and $20 \%$ in Japan has a foreign operation proxy of:

$$
\text { Foreign_Info }{ }_{i, j, t}=0.3 \cdot R_{\text {Pharma,t }}^{\text {USA }}+0.2 \cdot R_{\text {Pharma }, \text { }}^{\text {Japan }} \text {. }
$$

Hence, Foreign_Info is a weighted measure of a firm's exposure (fraction of sales) to a specific country or region combined with economically relevant information (corresponding foreign industry return). ${ }^{13}$

\subsection{Summary Statistics}

Our final sample consists of 13,258 individual firms from 22 developed countries with a total of 666,545 firm-month observations. Panel A of Table 1 provides summary statistics.

[Insert Table 1 about here]

\footnotetext{
${ }^{12}$ Local industry indices for all of the 59 geographic segments are obtained from Datastream. Specifically, we use the Industry Classification Benchmark (ICB) Supersector (Level 3 sector in Datastream) classifications, which uniquely assigns a firm to one of 19 industries. In order to match U.S. stocks (which are classified according to the Global Industry Classification System, GICS) with the ICB system we utilize an updated version of the GICS - ICB concordance table from Bekaert et al. (2011). We thank Campbell Harvey for providing us with the concordance table.

${ }^{13}$ We follow Huang (2015) and use industry returns from the respective geographic segments as measures of economic performance instead of macroeconomic indicators. The use of equity returns instead of macro variables has several advantages: equity returns are available in real-time for investors, are historical stored at a monthly frequency for all countries in CRSP and Datastream, are forward-looking, and aggregate new economic information - including macroeconomic information. In contrast, data availability of macroeconomic indicators is often limited, available at most at a quarterly or annual frequency, published with a certain delay and often revised after their first publication.
} 
Columns (1) - (3) of Panel A in Table 1 assign each country into the different geographical subsamples Asia-Pacific, Europe, and North America. Columns (4) - (5) report the number of firms and firm-month observations per country. The USA has the highest number of unique firms $(3,314)$, followed by the U.K. $(1,724)$, and Japan $(1,424)$. The countries with the lowest number of unique firms are Portugal (41), Ireland (55), and Austria (92). Column (6) reports the percentage share of foreign sales with regard to total sales. We find that the countries with the highest percentage share of foreign sales are Finland (65.87\%), the Netherlands (63.04\%), and Ireland (62.38\%), while Japan (25.26\%), Australia (27.65\%), and New Zealand (30.40\%) display the lowest percentage share of foreign sales. Finally, columns (7) - (9) show the minimum, average, and maximum values of Foreign_Info across countries. We document that the average value of Foreign_Info over all countries is $0.48 \%$ with Switzerland (0.66\%), Denmark $(0.63 \%)$, and Singapore $(0.61 \%)$ displaying the highest value and Japan $(0.27 \%)$, the USA (0.33\%), and Portugal (0.39\%) displaying the lowest values.

Since our main variable of interest - Foreign_Info - is based upon foreign sales, we report additional information of a country's foreign sales distribution in Panel B of Table 1. Column (1) reports the average Herfindahl index of a country's foreign sales distribution documenting the amount of concentration in foreign sales activities. We find that foreign sales are most concentrated in Australia (0.67), Hong Kong (0.63), and Japan (0.62), while they are least concentrated in Sweden (0.43), Finland (0.44), and Switzerland (0.44). We also report the percentage share of foreign sales for each individual country with regard to different geographical areas (columns (2) - (5)) and with regard to their top 3 foreign sales countries (columns (6) - (12)). As an example, we find that U.K. multinationals sell 39.8\% of their products to North America, 35.6\% to Europe, and 11.3\% to Asia-Pacific with the USA, Germany, and France being their top 3 foreign sales countries. 


\section{Foreign Information and Future Stock Returns Worldwide}

\subsection{Univariate Portfolio Sorts}

The first section of our empirical analysis conducts univariate portfolio sorts. Portfolio sorts represent an intuitive and nonparametric way to examine cross-sectional variation in expected returns with respect to a common predictor variable. They also provide an important cross-check for more formal regression tests, which we utilize in the subsequent section.

In each month $t$ of our sample period, we sort stocks into five quintiles based on Foreign_Info $o_{i, j, t-1}$. Then, we report the average value-weighted US-dollar excess returns for these quintile portfolios at month $t$ as well as differences in average excess returns between quintile portfolio 5 (high Foreign_Info) and quintile portfolio 1 (low Foreign_Info) with corresponding statistical significance level. ${ }^{14}$ We focus on value-weighted portfolio tests in our base-case scenario to limit the influence of small firms; however, our results are also robust if we base our sorts on an equal-weighted scheme instead (see Section 3.4). Portfolio sorts are conducted for five different regions: the worldwide sample (Global), the worldwide sample excluding the USA (Global ex. USA), Asia-Pacific, Europe, and North America. ${ }^{15}$ Results are reported in Panel A of Table 2.

\section{[Insert Table 2 about here]}

Panel A documents that stocks with high Foreign_Info have significantly higher future returns than stocks with low Foreign_Info. In the pooled global sample, stocks in the quintile with lowest

\footnotetext{
${ }^{14}$ In order to adjust for serial correlation in monthly stock returns, we use Newey and West (1987) standard errors with 12 lags in the statistical tests.

${ }^{15}$ We impose a minimum gap of 6 months between the portfolio formation period and the fiscal year end period from which the geographic segment data is taken. The procedure ensures that the geographic segment information of each multinational firm is publicly known at the start of the portfolio formation period and could have been used by investors in real time.
} 
(highest) Foreign_Info earn an average future monthly excess return of $0.15 \%$ (1.00\%). The return spread between quintile portfolio 5 and 1 is $0.85 \%$ per month, which is statistically significant at the $1 \%$ significance level. This monthly return spread translates into an annual spread of $10.20 \%$. Panel A also reports the relationship between Foreign_Info and future returns for different geographical areas. We find that the monthly return spread between stocks with high Foreign_Info and stocks with low Foreign_Info is positive for all geographical subsamples, i.e., for the global sample excluding the USA (0.63\%), AsiaPacific $(0.81 \%)$, Europe $(0.38 \%)$, and North America $(0.81 \%)$. The spread in returns is statistically significant (at least at the 5\% significance level) for all geographical subsamples except for Europe.

Panel B of Table 2 reports risk-adjusted excess returns for each quintile portfolio and the 5-1 difference portfolio (the long-short return spread based on Foreign_Info). We employ a regional version of the Carhart (1997) four-factor model to adjust the returns with respect to four common risk factors: the market (MKT), a portfolio going long in small stocks and going short in large stocks (SMB), a portfolio buying value stocks and selling growth stocks (HML), and a portfolio going long past winner stocks and shorting past loser stocks (UMD). The corresponding risk factors for each specific region are obtained from the webpage of Andrea Frazzini. ${ }^{16}$

Similar as for excess returns, we find that monthly spreads in Carhart (1997) alphas between quintile 5 (high Foreign_Info) and quintile 1 (low Foreign_Info) are positive and statistically significant (at least at the $10 \%$ significance level) for the worldwide sample $(0.89 \%)$, the worldwide sample excluding the USA (0.65\%), Asia-Pacific (0.69\%), and North America (0.94\%). We also document a

\footnotetext{
${ }^{16}$ Asness et al. (2014) study a multi-factor model in a sample of developed markets, which is very similar to the set of countries used in this paper. We thank Andrea Frazzini for making the risk factors available on his homepage http://www.econ.yale.edu/ af227/data_library.htm.
} 
positive, but statistically insignificant spread of $0.43 \%$ for Europe (t-statistic of 1.34 ).${ }^{17}$ In order to better understand the risk characteristics of the long-short return spread based on Foreign_Info, we look at the factor loadings of the 5-1 difference portfolio. Our results for the global sample indicate negative exposures to the market, the SMB factor, and the UMD factor as well as a positive exposure to the HML factor. Hence, a portfolio strategy buying high Foreign_Info stocks and selling low Foreign_Info stocks is countercyclical and tends to buy large stocks, value stocks, as well as stocks with low past returns. ${ }^{18}$

Finally, Panel $\mathrm{C}$ of Table 2 reports risk-adjusted returns for the global and regional quintile portfolios and the 5-1 difference portfolios using an international version of the Fama and French (2015a) five-factor model. Fama and French (2015a) propose a novel factor model based on the five risk factors MKT, SMB, HML, RMW and CMA. RMW is the return on a portfolio buying stocks with robust profitability and shorting stocks with weak profitability. CMA is the return on a portfolio buying stocks with conservative investment and selling stocks with aggressive investment. Fama and French (2015b) construct international risk factors according to their five-factor model for multiple regions. ${ }^{19}$ The alphas for the 5-1 difference portfolios based on the five-factor model are similar to the alphas obtained from the four-factor model. They are statistically significant for the Global sample (0.69\%), Global ex USA $(0.57 \%)$, Asia-Pacific $(0.69 \%)$ and North America (0.64\%). The alpha of Europe remains positive but

\footnotetext{
${ }^{17}$ We obtain similar results when risk-adjusting the raw returns for a regional version of the Fama and French (1993) three-factor model and the Sharpe (1964) one-factor CAPM model.

${ }^{18}$ Please note that the negative loading on the SMB factor is mainly driven by a few stocks with very large market capitalization. Based on an equal-weighted regression analysis in Section 4.1, we find that the Foreign_Info effect is stronger for small caps.

${ }^{19}$ Fama and French (2015b) construct their five risk factors using slightly different regional definitions compared to us. Specifically, they construct different sets of risk factors for both Asia-Pacific ex Japan and Japan, respectively. In contrast, our regional definition of Asia-Pacific includes Japan following Assness et al. (2014). The results for AsiaPacific in Table 2 Panel $\mathrm{C}$ are calculated using the risk factors for Asia-Pacific ex Japan from Fama and French (2015b). However, we obtain similar results when we use the Japan risk factors instead or when we use both sets of risk factors jointly. Data on the five factor model are available at the webpage of Kenneth French: http://mba.tuck.dartmouth.edu/pages/faculty/ken.french/data library.
} 
statistically insignificant (t-statistic of 1.47). We find that the returns on the 5-1 difference portfolios are not significantly related to the RMB or the CMA factor in any geographical region.

In summary, the results of Table 2 show that Foreign_Info has predictive power for future stock returns of multinational firms both worldwide as well as for different geographical subsamples and that conventional asset pricing models, such as the Carhart (1997) four-factor model and the Fama and French (2015a) five-factor model, fail to explain the return spread due to Foreign_Info.

\subsection{Multivariate Regressions}

We now proceed to run Fama and MacBeth (1973) regressions to analyze the predictive power of Foreign_Info on future returns when controlling for a wide array of different firm characteristics. The Fama and MacBeth (1973) regression procedure follows two steps. In the first step, we estimate the following cross-sectional regression in each month:

$$
R_{i, t}=\beta_{0, t}+\beta_{1, c, t}+\beta_{2, t} \text { Foreign_Info } o_{i, j, t-1}+\beta_{3, t}^{\prime} Y_{i, t-1}+\beta_{4, t}^{\prime} Z_{i, t}+\varepsilon_{i, t},
$$

where $R_{i, t}$ denotes firm $i$ 's excess return in month $t, \beta_{0, t}$ denotes the intercept, $\beta_{1, c, t}$ is a countryspecific dummy variable which is equal to one if firm $i$ is from country $c$ and zero otherwise, $Y_{i, t-1}$ is a vector of firm controls measured in month $t-1$ and constructed in a way that firm controls are publicly known at the beginning of month $t$, and $Z_{i, t}$ is a vector of control variables measured contemporaneously to $R_{i, t}$ in month $t$.

The second step tests whether the average coefficient estimates are significantly different from zero. Note that this procedure accounts for time fixed effects and controls for different means of firms from different countries (country fixed effects). Standard errors are computed using the Newey and West (1987) adjustment with 12 lags to account for heteroscedasticity and autocorrelation. 
We include a comprehensive set of firm characteristics (measured in month $t-1$ ) in our asset pricing tests: a firm's Beta, Size (Banz, 1981), book-to-market ratio BM (Basu, 1983), $R_{i, t-12: t-2}$ (the cumulative medium-term return of stock $i$ from month $t-12$ through $t-2$, to account for stock momentum as in Jagadeesh and Titman, 1993), $R_{i, t-1}$ to account for short term reversal (Jagadeesh, 1990; Lo and McKinley, 1990), Turnover (Rouwenhorst, 1999; Ibbotson et al., 2013), Idio_Vola to account for the idiosyncratic volatility effect (Ang et al., 2006; Ang et al., 2009), as well as Dom_Ind_Ret $t_{i, t-1}$ and Dom_Ind_Ret $t_{i, t-12: t-2}$ to account for industry momentum (Grinblatt and Moskowitz, 1999; Nijman et al., 2004). Finally, to control for potential autocorrelation in Foreign_Info and industry momentum, we also include the contemporaneous variables Dom_Ind_Ret $t_{i, t}$ and Foreign_Info $o_{i, j, t}$ in our regression setup. Definitions and summary statistics of all control variables are contained in Tables A.1 and A.2 of the Appendix.

\section{[Insert Table 3 about here]}

Specifications (1) - (5) present the regression results for the pooled worldwide sample and the geographical subsamples. In line with previous research we confirm a standard set of cross-sectional return patterns: Size (-), BM (+), $R_{i, t-1}(-)$, Turnover (-), Idio_Vola (-), and Dom_Ind_Ret ${ }_{i, t-1}(+)$ are significant predictors for the cross-section of future stock returns worldwide. We also find that the returns of multinational firms in all regions are significantly correlated with the contemporaneous domestic industry returns $\left(D_{o m}{ }_{-}\right.$Ind_Ret $\left._{i, t}\right)$ and the contemporaneous industry returns in their foreign geographical segments (Foreign_Info $\left.o_{i, j, t}\right)$. More importantly in our context, we document that the marginal effect of Foreign_Inf $o_{i, j, t-1}$ is positive and statistically significant both for the worldwide 
sample as well as for all geographical subsamples. ${ }^{20}$ Hence, the Foreign_Info effect is different from the impact of other firm characteristics and is not subsumed by stock return reversal, momentum and/or industry momentum.

Specifications (6) and (7) repeat the Fama and MacBeth (1973) regression with the global sample; however, instead of one-month-ahead returns we predict cumulated two- and three-month-ahead returns. In all specifications we report a positive and statistically significant impact of Foreign_Info $o_{i, j, t-1}$ on future returns. Hence, the effect is likely not to be driven by overreaction of stock market investors; instead the effect seems to be long-lasting and permanent.

In specification (8) we evaluate the predictive power of Foreign_Info_Market ${ }_{i, \mathrm{j}, t-1}-$ computed as the sales-weighted average of country-level (instead of industry-level) returns in the relevant foreign geographical segments. This alternative measure is proposed by Nguyen (2012), who documents that Foreign_Info_Market ${ }_{i, \mathrm{j}, t-1}$ significantly predicts future returns of U.S. multinational firms. Using our worldwide sample, we can provide an out-of-sample check to analyze which measure of foreign information is more important to predict multinationals' future stock returns. We find a positive and significant impact of Foreign_Info $o_{i, \mathrm{j}, t-1}$ on future returns whereas the Foreign_Info_Market ${ }_{i, \mathrm{j}, t-1}$ measure is not statistically significant. Hence, our results indicate that return predictability of multinationals comes from industry-related information instead of market-related information. Hence, we complement previous findings by Hou (2007) who documents that the lead-lag effect between big firms and small firms in the USA is predominantly an intra-industry phenomenon. We contribute by

\footnotetext{
${ }^{20}$ Interestingly, the predictive power of Foreign_Info is also highly significant for European multinationals, although we did not detect predictive power in the portfolio sorts in Section 3.1. Note that these results do not contradict each other. The portfolio tests in the previous section are based on value-weighted sorts whereas each return observation receives an equal weight in the multivariate regression analysis. This finding suggests that the Foreign_Info effect for multinationals from Europe is stronger when we use equal-weighted portfolio sorts, which we confirm in Section 3.4 below.
} 
demonstrating that not only domestic, but also foreign industry returns are relevant for the predictability of multinational firms.

Finally, in specifications (9) and (10) we run Fama and MacBeth (1973) regressions using riskadjusted returns of individual firms, instead of excess returns, as the dependent variable. We compute individual risk-adjusted returns for firm $i$ in month $t$ as the difference between firm $i$ 's excess return and its expected factor return based on the Carhart (1997) four-factor model in month $t$ :

$$
R_{i, t}^{a d j}=R_{\mathrm{i}, \mathrm{t}}-\beta_{i, 1} M K T_{i, t}-\beta_{i, 2} S M B_{i, t}-\beta_{i, 3} H M L_{i, t}-\beta_{i, 4} U M D_{i, t}
$$

where $R_{i, t}^{a d j}$ denotes the risk-adjusted return of firm $i$ in month $t$ and $\beta_{i, k}$ is firm $i$ 's factor loading with respect to the different risk factors $k(k=1, \ldots, 4)$. To compute risk-adjusted returns, we use monthly risk factors (MKT, SMB, HML, UMD) for individual countries from Asness et al. (2014) and Hau and Lai (2014). Following Fama and French (1992) and Cao et al. (2015), we estimate the factor loadings in (3) for each firm using a time-series regression over the entire sample period. ${ }^{21} \mathrm{We}$ require a firm to have at least 36 non-missing observations to estimate the betas.

We calculate two alternative versions of risk-adjusted returns: In specification (9), we use domestic risk factors of the multinational firm's home country in the computation. However, one could argue that the domestic risk factors do not adequately capture the risk exposure of a multinational firm as multinationals operate in multiple countries. Therefore, in specification (10), we also use sales-weighted risk factors in the computation, i.e., hypothetical risk factors that are constructed as the sales-weighted

\footnotetext{
${ }^{21}$ Fama and French (1992) and Avramov and Chordia (2006) show that estimating the factor loadings over the entire sample yields the same results as rolling window estimates with past data. We use the entire sample in order to increase estimation efficiency of the factor loadings. However, we obtain similar results when we use rolling estimates.
} 
average of country-specific risk factors. ${ }^{22}$ In both cases, we again find that Foreign_Inf $o_{i, \mathrm{j}, t-1}$ remains positive and statistically significant.

To summarize, we find strong evidence that the predictability effect due to Foreign_Info is different from the effect of observable firm characteristics, long-lasting, and not explained by countryspecific risk factors.

\subsection{Foreign Information vs. Industry Momentum}

The foreign information effect is conceptually related to industry momentum. Grinblatt and Moskowitz (1999) document strong and prevalent momentum in U.S. industry components of stock returns which accounts for much of the individual stock momentum anomaly. In addition, Nijman et al. (2004) find that positive returns of momentum strategies in European stock markets are partly driven by industry momentum. The difference between Foreign_Info and industry momentum is that Foreign_Info accounts for past industry returns of a firm's foreign sales markets in contrast to past domestic industry returns.

This section aims to isolate the predictability effect of Foreign_Info from domestic industry momentum. Although our multivariate regressions in Section 3.2 demonstrate that the marginal impact of Foreign_Info remains statistically significant when controlling for past industry returns, we now take a closer look at the joint dynamics of both effects in portfolio double sorts.

In a first step, we first sort all stocks in the global sample into quintile portfolios based on Dom_Ind_Ret $t_{i, t-1}$. Then, we again sort the stocks within each portfolio into five quintiles based on

\footnotetext{
${ }^{22}$ Recall the introductory example from the introduction, where a U.K.-based pharma company has $50 \%$ of its sales located in the U.K., 30\% in the USA, and 20\% in Japan. The sales-weighted risk factors of this firm are constructed as 0.5 times the U.K. risk factors, 0.3 times the U.S. risk factors, and 0.2 times the Japan risk factors. Note that this composition will be firm-specific and time-varying when sales distributions change over time.
} 
Foreign_Info $o_{i, j, t-1}$. This way, we can study the predictability effect of Foreign_Inf $o_{i, j, t-1}$ while fixing different levels of domestic short-term industry momentum. We report the monthly risk-adjusted returns according to the Carhart (1997) four-factor model for the 25 industry momentum $\times$ Foreign_Info porfolios in Panel A of Table $4 .^{23}$

\section{[Insert Table 4 about here]}

We find - within four of five quintiles (except the one with the highest short-term industry momentum) - that the four-factor alpha of the high Foreign_Info portfolio is larger than the alpha of the small Foreign_Info portfolio and that the differences are economically large and statistically significant. The average monthly spread in alphas amounts to $0.72 \%$; that is, it is slightly reduced as compared to the return spread of $0.89 \%$ from the univariate sorts. Hence, short-term industry momentum is related to Foreign_Info, but it only accounts for a small part of the effect.

Panel B of Table 4 presents portfolio double sorts based on Dom_Ind_Ret ${ }_{i, t-2: t-12}$ and Foreign_Info $o_{i, \mathrm{j}, t-1}$. We find that the four-factor alphas of the high Foreign_Info portfolio is larger than the return of the small Foreign_Info portfolio in all five quintiles. The return differences are statistically significant in four out of five quintiles with an average monthly spread of $0.54 \%$. Hence, as before, the average monthly spread in alphas due to Foreign_Info is slightly reduced when accounting for mediumterm industry momentum, but remains statistically and economically important.

In summary, based on portfolio double sorts we provide strong evidence that the predictability effect based on Foreign_Info is related to but clearly different from the effect of industry momentum.

\footnotetext{
${ }^{23}$ We obtain similar results when we reverse the sorting order or when we use geographical subsamples in the empirical analysis.
} 


\subsection{Robustness}

This section provides additional analyses and stability checks to provide robustness for our main empirical results. To do so, we perform univariate portfolio sorts on the global sample and adjust excess returns for each quintile portfolio and the 5-1 difference portfolio (the long-short return spread based on Foreign_Info) using a regional version of the Carhart (1997) four-factor model (as in Panel B of Table 2). Table 5 reports results of different stability and robustness checks.

\section{[Insert Table 5 about here]}

Column (1) repeats the baseline result for value-weighted portfolio sorts as shown in the first column of Panel B in Table 2. Column (2) reports the results when we apply an equal-weighted procedure instead of a value-weighting sorting procedure. Column (3) addresses concerns that our results might be driven by exchange rate effects as the returns in our base-case specification are converted to USD. Hence, we repeat our portfolio sorts with risk-adjusted returns denominated in local currency. Column (4) reports the results of portfolio sorts when we skip five trading days between the measurement period of Foreign_Info $o_{i, j, t-1}$ and the start of the portfolio formation period. In column (5), we address concerns that the predictability effect could be driven by small firms and caused by lead-lag effects along the lines of Hou (2007). ${ }^{24}$ To investigate if our results are caused by lead-lag effects related to firm size, we repeat the portfolio sorts using only the $20 \%$ largest firms in each country and month. Column (6) excludes all firms from our sample that operate in the financial sector. ${ }^{25}$ In column (7), we exclude firms with a total foreign sales share of less than $20 \%$ to ensure that our results are not driven by firms with a negligible

\footnotetext{
${ }^{24}$ Hou (2007) finds that the returns of small firms are predictable by lagged returns of large firms in the same country. Large firms, on the other hand, exhibit no predictability.

${ }^{25}$ Financial firms are often excluded in empirical asset pricing tests as the characteristics of accounting variables can be very different from firms operating in the real economy.
} 
fraction of foreign sales. ${ }^{26}$ Column (8) excludes all multinational firms with foreign sales in emerging markets. If firms with emerging market exposure are more risky and command higher expected returns, it could be the case that our sorts on Foreign_Info implicitly capture emerging market risk. Finally, in column (9), we exclude all firms from the sample that do not exclusively report individual countries in all of their geographical segments. As noted before in Section 2.1, multinational firms are allowed to aggregate the sales from two or more countries and to report a region instead of individual countries which adds a certain amount of noise to the geographical segment data. ${ }^{27}$

In all of our robustness and stability checks, we continue to find a significant impact of Foreign_Info on average future returns of multinationals. Our results indicate that the predictability effect due to Foreign_Info is robust to the portfolio sorting weighting procedure, exchange rate dynamics, gaps between the measurement period of Foreign_Info and the portfolio formation period, as well as the exclusion of small firms, financial firms, firms that have a low share of foreign sales, firms with foreign sales in emerging markets, and firms that aggregate sales to geographical regions.

\section{Comovement of Individual Country Portfolio Returns}

Having established a profound and robust positive link between Foreign_Info and future stock returns on a global scale, we now examine the degree of comovement of the country-specific return spreads due to Foreign_Info across all countries. In order to perform this analysis, we first compute the excess returns at month $t$ generated by a trading strategy of going long stocks with high Foreign_Info and going short stocks with low Foreign_Info at month $t$-1. Due to the limited number of multinationals in some smaller countries in our sample, we sort stocks into tercile portfolios instead of quintiles.

\footnotetext{
${ }^{26}$ The results are qualitatively similar when we use different cut-off points such as $10 \%$ or $30 \%$.

${ }^{27}$ Deleting all firms that do not exclusively report individual countries results in a loss of more than $50 \%$ of all observations in our sample.
} 
Columns (1) - (4) of Panel A in Table 6 report the results of country-individual value-weighted portfolio sorts. We report the average monthly returns for the low Foreign_Info portfolio, the high Foreign_Info portfolio, and the high-low return spreads with respective t-statistics. We also report the country-specific alphas (including t-statistics) from a regression of the Foreign_Info return spread on the Carhart (1997) risk factors in columns (5) and (6).

\section{[Insert Table 6 about here]}

We observe that the returns of the long-short return portfolio are positive for 20 out of 22 countries. However, the positive return spreads are not always statistically significant. In particular, we find that the long-short return spread due to Foreign_Info is statistically significant for 9 out of 22 countries, and the Carhart (1997) four-factor alphas are significant for 11 of the 22 countries. The highest alphas are found for Belgium, followed by Denmark, Switzerland, and Singapore.

We then continue and examine the degree of comovement of the Foreign_Info return spreads across countries. Column (7) reports the average correlation of a country's return spread with respect to all other countries' return spreads. Our results indicate that the return spreads display a positive, but only mild average correlation of 0.12 among each other. The countries with the highest average correlation (with the remaining countries) are the U.S. (0.23), Switzerland (0.21), and France (0.20), while New Zealand (-0.06), Portugal (0.06), Austria and Finland (both 0.07) exhibit the lowest correlations.

To check whether global time-varying factors can explain the Foreign_Info effect across countries, we run a global factor model and regress the country-specific Foreign_Info return spreads on the global Foreign_Info return spread. ${ }^{28}$ We report the beta-coefficient (including t-statistics), the alpha

\footnotetext{
${ }^{28}$ To remain consistent with our empirical analysis in this section, we also sort stocks into tercile portfolios instead of quintile portfolios on a global scale. When computing the global return spread due to Foreign_Info in the time-
} 
(including t-statistics), and the R-squared of this regression for each individual country in columns (8) (12). Our results indicate that the country-specific Foreign_Info return spread loads significantly positive on the global Foreign_Info return spread in 15 of 22 countries. However, the global Foreign_Info return spread is frequently not able to explain the country-specific alpha: In 9 out of 22 countries the return spread due to country-specific Foreign_Info remains statistically significant when accounting for the global Foreign_Info effect. Moreover, the global factor model only shows a relatively low explanatory power in terms of R-squares (ranging from 0.01 to 0.31 ) for each country and seems, at most, to play a minor role in explaining country-specific Foreign_Info return spreads.

Finally, to obtain additional insight into the factor structure of the 22 country-specific Foreign_Info return spreads, we perform a principal component analysis in Panel B of Table 6. Our results, again, indicate that there is only a modest degree of commonality in the variation of Foreign_Info return spreads across countries. More precisely, we find that the first principal component explains $19.22 \%$ of the total variation in Foreign_Info return spreads across all countries. Furthermore, adding the second and third principal component only marginally increases explanatory power, as the first two (three) principal components explain $27.06 \%$ (33.92\%) of the overall variation. ${ }^{29}$

To sum up, we find strong evidence that the country-specific Foreign_Info return spreads only display a modest commonality among each other and that the time-series variation of the Foreign_Info effect is mainly driven by time-varying country-specific factors.

series regression for country $i$, we exclude country $i$ 's stocks. This removes potential endogeneity problems when regressing the country-specific Foreign_Info return spread on the global Foreign_Info return spread for each individual country.

${ }^{29}$ In addition, we investigate how the variations of the country-specific Foreign_Info return spreads generally decompose into cross-country and temporal variations. To do so, we pool the individual Foreign_Info return spreads and run an OLS regression with country-fixed effects. These country-fixed effects explain less than $1 \%$ of the overall variance. We then add monthly time-series fixed effects in the regression setup which increases the overall $\mathrm{R}^{2}$ to 0.15 . Hence, $85 \%$ of the overall variation in returns is driven by factors which are not covered by country- or time-fixed effects, i.e., driven by country-specific time-varying factors. 


\section{Which Factors Drive the Foreign Information Effect?}

We now shed light on possible drivers of the Foreign_Info effect. We argue (in line with Nguyen (2012) and Huang (2015)) that the predictive power of Foreign_Info is caused by investors' lack of attention to foreign information. According to this explanation, Foreign_Info reflects information about future growth opportunities in the geographic segments in which a multinational firm operates. Because of limited attention and information processing constraints of (some) investors, the prices of multinational firms do not instantly react to new information about future economic prospects of the firms' geographic segments. Hence, the key prediction of this hypothesis is that multinational firms with higher (lower) levels of investor attention should exhibit lower (higher) predictability by Foreign_Info. We investigate this hypothesis on the firm level (Section 5.1), the time-series level (Section 5.2), and across countries (Section 5.3).

\subsection{Firm Characteristics}

In this section we investigate whether limited attention is a main driver of the Foreign_Info effect on the firm level. To do so, we examine a broad range of variables that are possibly associated with investor attention on the firm level. All proxies are at least available on a quarterly frequency. ${ }^{30}$

Size is a firm's log market capitalization in USD at the end of previous June. It is a common proxy for attention as small firms are generally less visible and receive less attention compared to large firms (e.g., Arbel et al., 1983; Hou and Moskowitz, 2005; Hou, 2007).

Res_Num_Ana is the number of equity analysts providing earnings forecasts for a firm (taken from Thomson Reuters I/B/E/S). Equity analysts are an important provider of firm-specific information

\footnotetext{
${ }^{30}$ We also describe all variables of this Section in Table A.1 and provide summary statistics in Table A.2 of the Appendix.
} 
and the number of analysts following a firm can be seen as a proxy for the overall amount of information produced about the firm (e.g., Brennan et al., 1993; Hong et al., 2000). As the number of analysts following a firm is highly correlated with firm size (Bushan, 1989), we follow the procedure of Hong et al. (2000), and orthogonalize analyst coverage with respect to size. ${ }^{31}$ Then we use the residuals of this regression as a proxy for investor attention.

Res_Ownership is defined as the residual percentage of shares outstanding held by institutional investors, orthogonalized with respect to size. Data on institutional ownership is taken from Lionshares. Institutional investors are generally considered to be better informed and have greater information processing capacities than individual investors (Badrinath et al., 1995; Boehmer and Kelley, 2009). Therefore, we expect firms with low levels of institutional ownership to respond more slowly to new information.

Res_Num_Investors is the number of institutional investors owning shares of a firm. Analogous to analyst coverage, the total number of institutional investors can be seen as a proxy for the amount of information produced about a firm. We also orthogonalize this measure with respect to size.

Geographical_Distance is the sales-weighted geographical distance between the resident country of a multinational firm and its respective geographic segments. ${ }^{32}$ We would expect that multinational firms with greater distance between the resident country and their respective geographic segments are prone to a greater predictability effect.

\footnotetext{
${ }^{31}$ Following Hong et al. (2000), we regress $\log (1+$ Num_Ana) on $\log ($ Size $)$ and use the residuals of this regression as our measure for analyst coverage. The analyst coverage of firms not covered by $\mathrm{I} / \mathrm{B} / \mathrm{E} / \mathrm{S}$ is set to zero.

32 Geographical distances between the capital cities of two countries are obtained from http://ec.europa.eu/programmes/erasmus-plus/tools/distance_en.htm.
} 
Cultural_Distance is the sales-weighted cultural distance between the resident country of a multinational firm and its respective geographic segments. Following Kogut and Singh (1988), we compute cultural distance based on the six cultural dimensions of Hofstede et al. (2010). ${ }^{33}$ The six cultural dimensions are: power distance, individualism, masculinity, uncertainty avoidance, long term orientation and indulgence. The cultural distance $C D_{i, j}$ measure between country $i$ and country $j$ is then given by

$$
C D_{i, j}=\frac{\sum_{k=1}^{6}\left(D_{i, k}-D_{j, k}\right)^{2} / \operatorname{VAR}\left(D_{k}\right)}{6}
$$

where $D_{i, k}$ is country $i$ 's score for cultural dimension $k$ and $\operatorname{VAR}\left(D_{k}\right)$ is the variance of dimension $k$. We expect multinational firms with greater cultural distance between their geographical segments to exhibit greater predictability.

Finally, Sales_Same_Language is the fraction of a firm's foreign sales from countries with the same official language as the firm's resident country. Recall the previous example where a firm is located in the United Kingdom and generates $50 \%$ of its sales in the UK, 30\% in the USA and 20\% in Japan. Sales_Same_Language for this firm is 0.3 because the official language in both the UK and the USA is English. A common language in the firm's resident country and geographical segments substantially simplifies the processing of value-relevant foreign information for domestic investors. Therefore, we expect firms with a higher value of Sales_Same_Language to exhibit less information frictions which in turn leads to a lower predictability effect by Foreign_Info.

Even if some investors exhibit limited attention which deters the incorporation of foreign information into prices, less informationally constrained investors (such as professional money managers) should attempt to arbitrage away the predictive power of Foreign_Info. However, limits to arbitrage

\footnotetext{
${ }^{33}$ The cultural dimensions of Hofstede et al. (2010) are available at http://www.geerthofstede.nl/dimension-datamatrix.
} 
potentially prevent these informed investors from fully arbitraging away the predictability effect (Shleifer and Vishny, 1997). Especially stocks with high idiosyncratic volatility are associated with higher arbitrage risk, which limits arbitrage activities of informed investors (e.g., De Long et al., 1990; Pontiff, 2006; Cohen and Lou, 2012; Stambaugh et al., 2015). This line of argument predicts that stocks with high idiosyncratic volatility should experience a higher predictability by Foreign_Info. Therefore, we also include Idio_Vola in our tests.

We construct a dummy variable, dummy $y_{i, t-1}$, which is equal to one if the corresponding attention proxy of multinational $i$ in the previous month is above the cross-sectional median of all firms. Then we run Fama-MacBeth regressions including the dummy and an interaction term between the dummy and Foreign_Info $o_{i, \mathrm{j}, t-1}$

$$
\begin{aligned}
R_{i, t}= & \beta_{0}+\beta_{1, c}+\beta_{2} \text { dummy }_{i, t-1}+\beta_{3} \text { Foreign_Info }_{i, j, t-1} \\
& +\beta_{4}\left(\text { dummy }_{i, t-1} \times \text { Foreign }_{\text {Info }_{i, j, t-1}}\right)+\beta_{5}^{\prime} Y_{i, t-1}+\beta_{6}^{\prime} Z_{i, t}+\varepsilon_{i, t} .
\end{aligned}
$$

A significantly positive coefficient estimate for $\beta_{4}$ implies that the predictability effect of Foreign_Info $o_{i, j, t-1}$ is higher for firms with low investor attention and vice versa. As in Table 3, we include our standard set of firm characteristics in the regression and control for country fixed effects. Table 7 presents the regression estimates and t-statistics for $\beta_{4}$ on the global sample. For brevity, we do not report the coefficient estimates for the control variables.

\section{[Insert Table 7 about here]}

We find that the predictive effect of Foreign_Info $o_{i, j, t-1}$ is significantly weaker for firms with high levels of investor attention as measured by firm size, residual analyst coverage, and residual number 
of institutional investors. The coefficient on the interaction term with residual institutional ownership is negative but not statistically significant. We also document a significantly weaker return predictability for firms with high Sales_Same_Language, which supports the argument that differences in language play an important role for the speed of information diffusion across international financial markets. Surprisingly, we do not find significant coefficients for the interaction terms including geographical distance and cultural distance. Hence, differences in language seem to be more important than geographical or cultural distance when accounting for investor inattention to foreign information.

Moreover, the predictive effect of Foreign_Info is larger for firms with high idiosyncratic volatility, supporting the argument that arbitrage risk prevents informed investors from fully exploiting the return predictability. This finding is consistent with Cohen and Lou (2012), who show that the returns on conglomerates are predictable and that the predictability effect is stronger for firms with high idiosyncratic volatility.

Overall, we interpret the results in Table 7 as consistent with the findings of Nguyen (2012) and Huang (2015) which support the gradual information diffusion explanation on a worldwide scale.

\subsection{Time-Series Variation with Respect to Investor Attention}

This section examines the time-series variation of the return spread due to Foreign_Info for individual countries. Specifically, we investigate whether changes in investor attention affect the magnitude of the return spread over time. We use search volume statistics from Google Trends (Search Volume Index, SVI) with regard to the main stock market index of a specific country as a direct measure of investor attention to financial information of that country. ${ }^{34}$ For example, we use the SVIs for "DAX

\footnotetext{
${ }^{34}$ Search frequency in Google is also used as a direct measure of investor attention in Da et al. (2011), Da et al. (2015), and Dimpfl and Jank (2016).
} 
30", "CAC 40" and "FTSE 100" as measures for investor attention with respect to financial information from Germany, France and the United Kingdom, respectively. When a search term does not provide a time-series of search frequencies, we use Google Insights' related search feature to determine which query is most related. Table A.3 reports the detailed search terms per country.

The SVI for a particular search term is provided by Google Trends on a weekly basis and is computed as the number of searches for that term scaled by its time-series average over the whole sample period. We download the SVI time-series for the 22 main stock market indices of all countries in our sample in the period from January 2004 to December 2013. Since our empirical analysis is based on a monthly frequency, we average the weekly observations on a monthly basis. Following Da et al. (2011), we use abnormal investor attention (ASVI) which is defined as the log of SVI of the current month minus the log of the median SVI during the previous two months in our empirical analysis.

The search technique in Google Trends enables us to differentiate between investors' attention with respect to domestic financial information and foreign financial information because Google Trends enables the user to select the specific country from which the queries are performed. For instance, Google Trends records how often individuals from the U.K. search for the U.S. stock market "S\&P 500". In this vein, we define abnormal foreign attention (Foreign_ASVI $\left.I_{c, t}\right)$ of investors in country $c$ as the valueweighted average of the ASVIs coming from individuals in country $c$ with respect to country $c$ 's top three foreign sales countries. ${ }^{35}$ For example, from Table 1 Panel B we know that the top three foreign sales countries of multinational firms from the U.K. are the United States (24.7\%), Germany (9.5\%), and France $(6.8 \%)$ with a total foreign share of $41 \%$. Thus, we measure the attention of investors from the U.K. with respect to foreign information as the value-weighted average of the ASVIs from the U.K. with

\footnotetext{
${ }^{35}$ Our results are robust to an equal-weighted average scheme of SVIs for country $c$ 's three main sales countries.
} 
respect to the main stock market indices of the United States $(24.7 \%$ / 41\% $=60.2 \%)$, Germany $(9.5 \%$ / $41 \%=23.2 \%)$, and France $(6.8 \% / 41 \%=16.6 \%) .{ }^{36}$ Similarly, we define abnormal domestic attention (Domestic_ASVI $I_{c, t}$ ) as the ASVI coming from individuals located in country $c$ with respect the main stock market index of country $c$ in month $t$. Finally, we define the overall attention of investors in country $c$ and month $t$ as the weighted average between domestic and foreign attention, where the weights correspond to the total shares of domestic and foreign sales

$$
\text { Overall_ASVI } I_{c, t}=w_{i, D} \text { Domestic_ASVI }{ }_{c, t}+w_{c, F} \text { Foreign_ASVI } I_{c, t} \text {, }
$$

where $\mathrm{w}_{c, D}$ denotes country $c$ 's percentage share of domestic sales and $\mathrm{w}_{c, F}$ denotes country $c$ 's percentage share of foreign sales as reported in Panel A of Table $1 .{ }^{37}$

Empirical Analysis. To investigate whether changes in investor attention influence the strength of the Foreign_Info effect over time, we regress country c's Foreign_Info return spread in month $t$ on country $c$ 's investor attention measures in month $t$-1. In particular, we estimate

$$
R_{c, t}^{L S}=\beta_{0}+\beta_{1, \mathrm{c}}+\beta_{2} A S V I_{c, t-1}+\beta_{5}^{\prime} V_{c, t-1}+\beta_{6}^{\prime} W_{c, t}+\varepsilon_{c, t}
$$

where $R_{c, t}^{L S}$ denotes country c's Foreign_Info return spread in month $t, A S V I_{c, t-1}$ denotes the abnormal attention measure for individuals in country $c$ in month $t$-1 (i.e., Overall_ASVI, Domestic_ASVI or Foreign_ASVI). We control for a vector of different country characteristics $V_{c, t-1}:$ Average_Size $e_{c, t-1}$, Average_Num_Analyst $_{c, t-1}$, Average_Ownership $p_{c, t-1}$, Average_Num_Investors ${ }_{c, t-1}$, as defined in Panel B of Table A.1 in the Appendix, measured at month $t-1$. We also add the local market return and market volatility (computed as the past 36 months rolling standard deviation of the market return) as

\footnotetext{
${ }^{36}$ Da et al. (2015) use a similar methodology where they aggregate ASVIs from different search terms to construct a single FEAR index.

37 The average correlation between Domestic_ASVI ${ }_{c, t}$ and Foreign_ASVI ${ }_{c, t}$ over all countries is 0.26 .
} 
contemporaneous control variables $W_{c, t}$ to the regression setup. We estimate Equation (7) using Ordinary Least Squares including country-fixed effects and Newey-West standard errors. Results are shown in Table 8 .

\section{[Insert Table 8 about here]}

In specification (1), we use Overall_ASVI as our only independent variable. In accordance with the notion that decreasing attention results in an increasing return spread due to Foreign_Info, we report a negative coefficient on Overall_ASVI. However, this coefficient is not statistically significant. We then proceed to separate overall attention into domestic and foreign attention in specification (2). We find a positive but insignificant relation between domestic attention (Domestic_ASVI) and the Foreign_Info return spread. However, and more importantly, we document a significantly negative coefficient on the foreign attention measure (Foreign_ASVI). Hence, a decrease in investors' attention with respect to foreign information in month $t-1$ results in a significant increase in the Foreign_Info return spread in month $t$. In unreported results (available upon request), we repeat regression model (2) for the 22 individual countries in our sample. We find that the relationship between Foreign_ASVI and the Foreign_Info return spread is negative in 17 out of 22 countries (with 8 countries showing a significantly negative relationship).

In Appendix A.4, we also investigate whether the magnitude of the Foreign_Info return spread across individual countries is related to the business cycle. We find that, generally, the Foreign_Info effect is stronger during recessions (see columns (1) and (2) of Table A.4). However, the impact of the recession indicator becomes insignificant when we control for Foreign_ASVI as an additional explanatory variable in the regression setup, while, at the same time, Foreign_ASVI remains highly statistically significant in all specifications (as seen in columns (3) - (6) of Table A.4). More details on the interesting 
relationships between business cycle dynamics and direct measures of investor attention (ASVI) are subsequently discussed in Appendix A.5.

In summary, our empirical methodology using Google Trends search volume enables us to separate investors' attention to domestic information and foreign information. We show that there exists a direct and significantly negative relationship between attention of investors to foreign information and the Foreign_Info return spread in the next month, while attention to domestic information is not significantly related to the return spread. Hence, our results strongly indicate that limited attention of investors with respect to foreign financial information increases the strength of the Foreign_Info effect.

\subsection{Country Characteristics}

Section 3 shows that Foreign_Info has a significant impact on future returns of multinational firms worldwide. However, the return difference between high Foreign_Info stocks and low Foreign_Info stocks strongly varies across countries as documented in Panel A of Table 6. Hence, we turn to the question which factors drive the differences in the magnitude of the Foreign_Info effect across countries. To do so, we regress country $c$ 's monthly Foreign_Info return spread, $R_{c, t}^{L S}$, on time-fixed country characteristics and the identical control variables as in Equation (7):

$$
R_{c, t}^{L S}=\beta_{0}+\beta_{1} \text { Characteristics }_{c}+\beta_{2}^{\prime} V_{c, t-1}+\beta_{3}^{\prime} W_{c, t}+\varepsilon_{c, t} .
$$

Equation (8) is estimated using Ordinary Least Squares with standard errors adjusted by the Newey-West method. We differentiate between two sets of country characteristics as explanatory variables: investor characteristics and macroeconomic variables. ${ }^{38}$

\footnotetext{
${ }^{38}$ All variables in the Section are also described in Table A.1 of the Appendix. Summary statistics are provided in Table A.2 of the Appendix.
} 
Investor Characteristics. We hypothesize that investors' inattention to foreign news slows the incorporation of foreign information into prices and increases the predictability of multinationals' stock returns. To proxy for investor inattention with regard to foreign information we use a country's domestic bias level (Domestic Bias). We obtain data for Domestic Bias for all countries in our sample from Chan et al. (2005) who examine how mutual fund managers allocate their investments between domestic and foreign equity markets. In particular, the Domestic Bias for country $c$ reflects the deviation of the share of the home country in its mutual fund holdings from the world market capitalization. ${ }^{39}$

Another potential explanation of the Foreign_Info effect is that investors lack the knowledge to understand and interpret foreign information when evaluating financial decisions. A testable implication of this hypothesis is that the Foreign_Info effect should be high in countries with low (financial) literacy of domestic stock market investors. To proxy for (financial) literacy of domestic investors we use the average years of schooling (Schooling) of a country's resident obtained from Barro and Lee (2013).

Finally, we also investigate the relationship between a country's trust level (Trust) and the magnitude of the foreign information effect. It is feasible that investors from countries with low levels of trust doubt foreign information and do not include it when evaluating financial investments. This behavior would subsequently enhance the magnitude of the foreign information effect in those countries. Data for Trust is obtained from Guiso et al. (2008). Specification (1) of Panel A in Table 9 reports the results.

[Insert Table 9 about here]

\footnotetext{
${ }^{39}$ In our regression analysis we also control for a country's Foreign Bias. The Foreign Bias for country $c$ reflects the extent to which foreign mutual fund managers underweight or overweight the share of country $c$ in their asset allocation (see Table A.1 in the Appendix and Chan et al. (2005)). On the cross-country level, Domestic Bias and Foreign Bias are negatively correlated with a correlation coefficient of -0.39 .
} 
As expected, we find that Domestic Bias has a positive and statistically significant impact on the magnitude of the Foreign_Info effect. This result is again consistent with the notion that limited attention of investors is the main driving force behind the Foreign_Info effect. We do not find evidence of a statistically significant impact of Schooling or Trust.

Macroeconomic Variables. The Foreign_Info effect is likely to be related to different macroeconomic country characteristics. In particular, we hypothesize that the magnitude of the Foreign_Info effect is higher in countries with segmented equity markets and strict capital flow restrictions. To test for these hypotheses we obtain data for a country's equity market segmentation (Segmentation) from Bekaert et al. (2011) as well as capital flow restrictions (Capital Flow Restrictions) from Chan et al. (2005). We also control for different macroeconomic/stock market variables such as a country's credit rating obtained from Chan et al. (2005) as well as stock market turnover and trading volume obtained from La Porta et al. (2006).

Specification (2) of Panel A in Table 9 shows that the only variable significantly positively related to the magnitude of the Foreign_Info effect is Segmentation, while Capital Flow Restrictions does not show a significant association. This result is in accordance with the idea that value-relevant foreign information particularly slowly dilutes into stock prices in countries with weakly integrated equity markets.

In the same vein as for the time-series analysis in Section 5.2, we also check whether the crosscountry drivers specifically capture under-reaction to foreign information or are also related to underreaction to domestic information. Hence, Panel B of Table 9 examines whether the cross-country characteristics also affect the under-reaction to information of domestic-only firms. As an proxy for investor attention to domestic information, we apply the high minus low post-earnings-announcement- 
drift following earnings surprises from day +2 to day $+126\left(P E A D_{c, t}\right)$ of country $c$ 's purely domestic firms in month $t .^{40}$ Following Griffin et al. (2010), $P E A D_{c, t}$ is measured as the difference between the buy-and-hold returns of stocks in the top (bottom) $60 \%$ of positive (negative) earnings surprises in the six months following the earnings announcement in month $t .^{41}$ The higher $P E A D_{c, t}$, the higher the underreaction of investors to domestic information.

In columns (1) and (2) of Panel B in Table 9, we perform the same regressions as in Panel A of Table 9, but use $P E A D_{c, t}$ as the dependent variable. We neither find a statistically significant relationship of $P E A D_{c, t}$ to investors' domestic bias nor to a country's segmentation. Hence, the time-fixed country characteristics that are significantly related to the Foreign_Info return spread in Panel A of Table 9 capture investors' under-reaction to foreign information and do not capture under-reaction to domestic information. $^{42}$

\section{Conclusion}

This paper analyzes whether value-relevant foreign information only gradually diffuses into stock prices of multinationals using a sample of firms from 22 developed countries worldwide. We proxy for a firm's exposure to foreign information (Foreign_Info) using the sales-weighted average of industry-level

\footnotetext{
${ }^{40}$ Since we are interested in level differences across countries, we cannot use the Domestic_ASVI variable based on Google Trends as defined in Section 5.2. Domestic_ASVI is computed as the number of searches scaled by the timeseries average over the whole sample period and can hence not be used to account for level differences between countries.

${ }^{41}$ We obtain earnings announcement dates, analyst forecasts and actual earnings for all firms with purely domestic sales in our sample from I/B/E/S. The calculation of the post-earnings-announcement-drift follows Griffin et al. (2010). In particular, the earnings surprise is calculated as the difference between the actual earnings per share in USD and the mean forecasted earnings per share in USD, scaled by the share price in USD at the end of the previous month.

${ }^{42}$ All of our results remain stable when we remove countries with less than 100 multinational firms from the empirical analysis and when we measure the high minus low post-earnings announcement-drift following earnings surprises from day +0 to day +126 (and hence include the immediate response to the information in earnings announcements).
} 
returns in the relevant foreign countries and show that Foreign_Info has significant predictive power for future stock returns on a global scale and across different geographical subsamples. Worldwide, stocks with the highest Foreign_Info outperform stocks with the lowest Foreign_Info on average by 0.85\% per month (10.20\% per annum). We document that this outperformance is not explained by traditional risk factors, firm characteristics, or industry momentum.

Having established a profound positive link between Foreign_Info and future stock returns on a global scale, we find that return spreads due to Foreign_Info across countries display a positive, but only modest correlation average. Hence, global factors only play a minor role in explaining the factor structure of the Foreign_Info return across countries.

Finally, we shed light on possible drivers of this effect. The Foreign_Info effect is particularly strong for small firms, firms with low analyst coverage, firms with a low number of institutional investors, firms with high idiosyncratic volatility, and firms with a larger amount of foreign sales from countries with a different language. Moreover, using data from Google Trends, we show that the countryspecific return spread due to Foreign_Info is significantly larger following months in which domestic investors have displayed low attention to foreign stock market information. We also discover that the Foreign_Info effect is particularly large in countries characterized by a strong domestic bias and segmented equity markets. Thus, our empirical findings are consistent with the notion that investors' inattention to foreign information is the main driver of the Foreign_Info effect. 


\section{Appendix}

Table A.1: Definitions of Main Variables

This table briefly defines the main variables used in the empirical analysis of this paper. Panel A presents the variables used in the asset pricing tests from Section 3 and 5.1, while Panel B defines the variables used in Sections 5.2 and 5.3. EST indicates that the variable is estimated or computed based on original variables from the respective data sources.

\section{Panel A: Main Variables used in Asset Pricing Tests in Section 3}

\begin{tabular}{|c|c|c|c|}
\hline Variable Name & Description & Source & Type \\
\hline Foreign_Info $_{i, j, t}$ & $\begin{array}{l}\text { Geographical sales-weighted industry return from } \\
\text { all non-domestic geographical segments of } \\
\text { multinational firm } i \text { in industry } j \text { at month } t \text { as } \\
\text { detailed in Section 2.2. }\end{array}$ & $\begin{array}{l}\text { Compustat, } \\
\text { Worldscope, } \\
\text { Datastream }\end{array}$ & $\begin{array}{l}\text { Time-Varying } \\
\text { Updated monthly }\end{array}$ \\
\hline$R_{i, t}$ & $\begin{array}{l}\text { Return of multinational firm } i \text { in month } t \text { denoted in } \\
\text { USD in excess of the } 1 \text { month U.S. T-bill rate. }\end{array}$ & CRSP, Datastream & $\begin{array}{l}\text { Time-Varying } \\
\text { Updated monthly }\end{array}$ \\
\hline$R_{i, t}^{a d j \_l o c a l}$ & $\begin{array}{l}\text { Risk-adjusted return of multinational firm } i \text { in } \\
\text { month } t \text { where the return is orthogonalized with } \\
\text { respect to the Carhart (1997) four factor model } \\
\text { from the firm's domestic country. }\end{array}$ & $\begin{array}{l}\text { CRSP, Datastream, } \\
\text { Asness, Frazzini and } \\
\text { Pedersen (2014) }\end{array}$ & $\begin{array}{l}\text { Time-Varying } \\
\text { Updated monthly }\end{array}$ \\
\hline$R_{i, t}^{a d j \_g e o}$ & $\begin{array}{l}\text { Risk-adjusted return of multinational firm } i \text { in } \\
\text { month } t \text { where the return is orthogonalized with } \\
\text { respect to the sales-weighted Carhart (1997) four } \\
\text { factors from the firm's respective geographical } \\
\text { segments. }\end{array}$ & $\begin{array}{l}\text { CRSP, Datastream, } \\
\text { Asness, Frazzini and } \\
\text { Pedersen (2014), Hau } \\
\text { and Lai (2014) }\end{array}$ & $\begin{array}{l}\text { Time-Varying } \\
\text { Updated monthly }\end{array}$ \\
\hline Beta & $\begin{array}{l}\text { Beta factor with respect to the domestic market } \\
\text { estimated with a rolling window over the past } 60 \\
\text { months. }\end{array}$ & CRSP, Datastream & $\begin{array}{l}\text { Time-Varying } \\
\text { Updated monthly }\end{array}$ \\
\hline Size & $\begin{array}{l}\text { Log market capitalization at the end of previous } \\
\text { June. }\end{array}$ & CRSP, Datastream & $\begin{array}{l}\text { Time-Varying } \\
\text { Updated monthly }\end{array}$ \\
\hline$B M$ & $\begin{array}{l}\text { Book value at the end of the previous calendar year } \\
\text { divided by the market capitalization at the end of } \\
\text { the previous year. }\end{array}$ & $\begin{array}{l}\text { CRSP, Compustat, } \\
\text { Datastream, } \\
\text { Worldscope }\end{array}$ & $\begin{array}{l}\text { Time-Varying } \\
\text { Updated monthly }\end{array}$ \\
\hline$R_{i, t-12: t-2}$ & $\begin{array}{l}\text { Cumulative return of firm i from month } t-12 \\
\text { through month } t-2 \text {. }\end{array}$ & CRSP, Datastream & $\begin{array}{l}\text { Time-Varying } \\
\text { Updated monthly }\end{array}$ \\
\hline Turnover & $\begin{array}{l}\text { Number of shares traded during a day divided by } \\
\text { the number of shares outstanding at the end of the } \\
\text { day, averaged over the past } 12 \text { months. }\end{array}$ & CRSP, Datastream & $\begin{array}{l}\text { Time-Varying } \\
\text { Updated monthly }\end{array}$ \\
\hline
\end{tabular}




\begin{tabular}{|c|c|c|c|}
\hline Idio_Vola & $\begin{array}{l}\text { Volatility of the residuals from a market model } \\
\text { regression estimated with a rolling window over the } \\
\text { past } 60 \text { months. }\end{array}$ & CRSP, Datastream & $\begin{array}{l}\text { Time-Varying } \\
\text { Updated monthly }\end{array}$ \\
\hline Dom_Ind_Ret $t_{i, t}$ & Domestic industry return of firm $i$ in month $t$. & Datastream & $\begin{array}{l}\text { Time-Varying } \\
\text { Updated monthly }\end{array}$ \\
\hline Dom_Ind_Ret $t_{i,-12: t-2}$ & $\begin{array}{l}\text { Cumulative domestic industry return from month } t-12 \\
\text { through } t-2 \text {. }\end{array}$ & Datastream & $\begin{array}{l}\text { Time-Varying } \\
\text { Updated monthly }\end{array}$ \\
\hline Foreign_Info_Market $_{i, j, t}$ & $\begin{array}{l}\text { Average sales-weighted market return from all non- } \\
\text { domestic geographical segments of multinational firm } \\
i \text { in month } t \text {. }\end{array}$ & $\begin{array}{l}\text { Compustat, } \\
\text { Worldscope, } \\
\text { Datastream }\end{array}$ & $\begin{array}{l}\text { Time-Varying } \\
\text { Updated monthly }\end{array}$ \\
\hline Res_Num_Ana & $\begin{array}{l}\text { Residual analyst coverage is the residual from a } \\
\text { cross-sectional regression of } \log (1+\text { Num_Ana }) \text { on } \log \\
\text { market capitalization at the end of month } t-1 \text {. }\end{array}$ & $\begin{array}{l}\text { CRSP, Datastream, } \\
\text { I/B/E/S }\end{array}$ & $\begin{array}{l}\text { Time-Varying } \\
\text { Updated monthly }\end{array}$ \\
\hline Res_Ownership & $\begin{array}{l}\text { Residual institutional ownership is the residual from a } \\
\text { cross-sectional regression of the percentage of shares } \\
\text { held by institutional investors on log market } \\
\text { capitalization at the end of month } \mathrm{t}-1 \text {. }\end{array}$ & $\begin{array}{l}\text { CRSP, Datastream, } \\
\text { Lionshares }\end{array}$ & $\begin{array}{l}\text { Time-Varying } \\
\text { Updated quarterly }\end{array}$ \\
\hline Res_Num_Investors & $\begin{array}{l}\text { Residual number of institutional investors is the } \\
\text { residual from a cross-sectional regression } \\
\log (1+\text { Num_Investors }) \text { on log market capitalization at } \\
\text { the end of month } t-1 \text {. }\end{array}$ & $\begin{array}{l}\text { CRSP, Datastream, } \\
\text { Lionshares }\end{array}$ & $\begin{array}{l}\text { Time-Varying } \\
\text { Updated quarterly }\end{array}$ \\
\hline Geographical_Distance & $\begin{array}{l}\text { Average sales-weighted geographical distance } \\
\text { between the capital of the multinational firm's } \\
\text { domestic country and the capitals of the respective } \\
\text { geographical segments. }\end{array}$ & $\begin{array}{l}\text { Compustat, } \\
\text { Worldscope, } \\
\text { Distance } \\
\text { Calculator from the } \\
\text { European } \\
\text { Comission }\end{array}$ & $\begin{array}{l}\text { Time-Varying } \\
\text { Updated annually }\end{array}$ \\
\hline Cultural_Distance & $\begin{array}{l}\text { Average sales-weighted cultural distance measure of } \\
\text { Kogut and Singh (1988) based on the six cultural } \\
\text { dimensions of Hofstede, Hofstede and Minkov (2010) } \\
\text { between the multinational firm's domestic country } \\
\text { and the respective geographical segments as detailed } \\
\text { in Section 5.1. }\end{array}$ & $\begin{array}{l}\text { Compustat, } \\
\text { Worldscope, } \\
\text { Hofstede, } \\
\text { Hofestede and } \\
\text { Minkov (2010) }\end{array}$ & $\begin{array}{l}\text { Time-Varying } \\
\text { Updated annually }\end{array}$ \\
\hline Sales_Same_Language & $\begin{array}{l}\text { Percentage of sales from countries with the same } \\
\text { official language as in the domestic country of the } \\
\text { multinational firm. }\end{array}$ & $\begin{array}{l}\text { Compustat, } \\
\text { Worldscope }\end{array}$ & $\begin{array}{l}\text { Time-Varying } \\
\text { Updated annually }\end{array}$ \\
\hline
\end{tabular}




\section{Panel B: Main Variables Used in Sections 5.2 and 5.3}

\begin{tabular}{|c|c|c|c|}
\hline Variable Name & Description & Source & Type \\
\hline$R_{c, t}^{L S}$ & $\begin{array}{l}\text { Country c's return spread due to Foreign_Info at } \\
\text { month } t \text {, i.e., the } 3-1 \text { (high-low) return of a portfolio } \\
\text { going long stocks with high Foreign_Info and going } \\
\text { short stocks with low Foreign_Info }\end{array}$ & $\begin{array}{l}\text { CRSP, } \\
\text { Datastream }\end{array}$ & $\begin{array}{l}\text { Time-Varying } \\
\text { Updated monthly }\end{array}$ \\
\hline Domestic_ASVI $I_{c, t}$ & $\begin{array}{l}\text { Google Trends SVI from individuals in country } c \text { for } \\
\text { the stock market index for country } c \text { in month } t \text {, as } \\
\text { detailed in Section 5.2. ASVI is the natural logarithm } \\
\text { of SVI at month t minus the natural logarithm of } \\
\text { median SVI during the previous two months. }\end{array}$ & Google Trends & $\begin{array}{l}\text { Time-Varying } \\
\text { Updated monthly }\end{array}$ \\
\hline Foreign_ASVI $I_{c, t}$ & $\begin{array}{l}\text { Equal-weighted average of ASVIs for country } c \text { 's } \\
\text { three main sales countries coming from individuals in } \\
\text { country } c \text { in month } t \text {. }\end{array}$ & Google Trends & $\begin{array}{l}\text { Time-Varying } \\
\text { Updated monthly }\end{array}$ \\
\hline Overall_ASVI $I_{c, t}$ & $\begin{array}{l}\text { Weighted average of Domestic_ASVI } I_{c, t} \text { and } \\
\text { Foreign_ASVI } I_{c, t} \text { with regard to domestic/foreign } \\
\text { sales frequencies, as detailed in Section 5.2. }\end{array}$ & Google Trends & $\begin{array}{l}\text { Time-Varying } \\
\text { Updated monthly }\end{array}$ \\
\hline$L B C_{c, t}$ & Local recession indicator for country $c$ in month $t$. & NBER, OECD & $\begin{array}{l}\text { Time-Varying } \\
\text { Updated monthly }\end{array}$ \\
\hline$G B C_{c, t}$ & Global recession indicator for country $c$ in month $t$. & OECD & $\begin{array}{l}\text { Time-Varying } \\
\text { Updated monthly }\end{array}$ \\
\hline Average_Size $e_{c, t}$ & $\begin{array}{l}\text { Equal-weighted average of Size in country } c \text { in month } \\
t .\end{array}$ & EST & $\begin{array}{l}\text { Time-Varying } \\
\text { Updated monthly }\end{array}$ \\
\hline Avg_Num_Analyst ${ }_{c, t}$ & $\begin{array}{l}\text { Equal-weighted average of Analyst Coverage in } \\
\text { country } c \text { in month } t \text {. }\end{array}$ & EST & $\begin{array}{l}\text { Time-Varying } \\
\text { Updated monthly }\end{array}$ \\
\hline Average_Ownership $_{c, t}$ & $\begin{array}{l}\text { Equal-weighted average of Institutional Ownership in } \\
\text { country } c \text { in month } t .\end{array}$ & EST & $\begin{array}{l}\text { Time-Varying } \\
\text { Updated monthly }\end{array}$ \\
\hline Avg_Num_Investors ${ }_{c, t}$ & $\begin{array}{l}\text { Equal-weighted average of Number of Investors in } \\
\text { country } c \text { in month } t \text {. }\end{array}$ & EST & $\begin{array}{l}\text { Time-Varying } \\
\text { Updated monthly }\end{array}$ \\
\hline Local Market Return $_{c, t}$ & Local market return in country $c$ in month $t$. & $\begin{array}{l}\text { Asness, Frazzini } \\
\text { and Pedersen } \\
(2014)\end{array}$ & $\begin{array}{l}\text { Time-Varying } \\
\text { Updated monthly }\end{array}$ \\
\hline Local Market Vola ${ }_{c, t}$ & $\begin{array}{l}36 \text { months rolling standard deviation of local market } \\
\text { return in month } t \text {. }\end{array}$ & EST & $\begin{array}{l}\text { Time-Varying } \\
\text { Updated monthly }\end{array}$ \\
\hline
\end{tabular}




\begin{tabular}{|c|c|c|c|}
\hline Variable Name & Description & Source & Type \\
\hline Domestic Bias $_{c}$ & $\begin{array}{l}\text { Domestic bias for host country } c \text { is defined as the } \\
\text { extent to which mutual fund holdings in the } \\
\text { domestic market of country } c \text { deviate from the } \\
\text { holdings of country } c \text { in the world market portfolio. }\end{array}$ & Chan et al. (2005) & $\begin{array}{l}\text { Time-invariant } \\
\text { Sample period: } \\
1999-2000\end{array}$ \\
\hline Foreign Bias $_{c}$ & $\begin{array}{l}\text { For each host country } j \text { compute the deviation from } \\
\text { mutual fund holdings with regard to country } c \text { and } \\
\text { country } c^{\prime} s \text { share in the world market portfolio. } \\
\text { Foreign bias for country } c \text { is then defined as the } \\
\text { average deviation for country } c \text { over all host } \\
\text { countries } j \text { (where } j \text { is not equal to } c \text { ). }\end{array}$ & Chan et al. (2005) & $\begin{array}{l}\text { Time-invariant } \\
\text { Sample period: } \\
1999-2000\end{array}$ \\
\hline Schooling $_{c}$ & Average years of schooling of a country's resident. & $\begin{array}{l}\text { Barro and Lee } \\
\text { (2013) }\end{array}$ & $\begin{array}{l}\text { Time-invariant } \\
\text { Average over: } \\
1995 \text { - } 2005\end{array}$ \\
\hline Trust $_{c}$ & $\begin{array}{l}\text { A country c's level of trust created by answers to } \\
\text { the question in the World Values Survey: } \\
\text { "Generally speaking, would you say that most } \\
\text { people can be trusted or that you have to be very } \\
\text { careful in dealing with people?" }\end{array}$ & $\begin{array}{l}\text { Guiso et al. } \\
\text { (2008) }\end{array}$ & $\begin{array}{l}\text { Time-invariant } \\
2003\end{array}$ \\
\hline Segmentation $_{c}$ & $\begin{array}{l}\text { Segmentation defined as the weighted difference } \\
\text { between the earning yields of country } c \text { 's industries } \\
\text { and the corresponding earning yields of industries } \\
\text { in global capital markets }\end{array}$ & $\begin{array}{l}\text { Bekaert et al. } \\
\text { (2011) }\end{array}$ & $\begin{array}{l}\text { Time-invariant } \\
\text { Average over: } \\
2001-2005\end{array}$ \\
\hline Capital Flow Restriction $_{c}$ & $\begin{array}{l}\text { Country c's capital flow restrictions measured by } \\
\text { the Economic Freedom Network index. This index } \\
\text { measures the restrictions countries impose on } \\
\text { capital flows by assigning lower ratings to } \\
\text { countries with more restrictions on foreign capital } \\
\text { transactions. }\end{array}$ & $\begin{array}{l}\text { Chan et al. } \\
(2005), \text { Economic } \\
\text { Freedom Network }\end{array}$ & $\begin{array}{l}\text { Time-invariant } \\
\text { Sample period: } \\
1999-2000\end{array}$ \\
\hline Credit Rating $c$ & $\begin{array}{l}\text { Country } c \text { 's credit rating which is based on a scale } \\
\text { of } 0 \text { to } 100 \text { as assessed by the Institutional Investor } \\
\text { Magazine. }\end{array}$ & $\begin{array}{l}\text { Chan et al. } \\
(2005) \text {, World } \\
\text { Competitive } \\
\text { Report }\end{array}$ & $\begin{array}{l}\text { Time-invariant } \\
\text { Sample period: } 2000\end{array}$ \\
\hline Turnover Ratio ${ }_{c}$ & $\begin{array}{l}\text { Country } c \text { 's turnover ratio, defined as the ratio of } \\
\text { the total value of stocks traded to the average } \\
\text { market capitalization. }\end{array}$ & $\begin{array}{l}\text { Chan et al. } \\
(2005), \text { Standard } \\
\& \text { Poor's } \\
\text { Emerging Stock } \\
\text { Market Factbook }\end{array}$ & $\begin{array}{l}\text { Time-invariant } \\
\text { Average over: } \\
1997 \text { - } 1999\end{array}$ \\
\hline Trading $_{c}$ & $\begin{array}{l}\text { Total value of stocks traded as a percentage of } \\
\text { GDP. }\end{array}$ & $\begin{array}{l}\text { La Porta et al. } \\
(2006)\end{array}$ & $\begin{array}{l}\text { Time-invariant } \\
\text { Average over: } \\
1996-2000\end{array}$ \\
\hline$P E A D_{c, t}$ & $\begin{array}{l}\text { High minus low post-earnings-announcement-drift } \\
\text { following earnings surprises from day }+2 \text { to day } \\
+126 \text { of a country c's purely domestic stocks in } \\
\text { month } t \text { following Griffin et al. (2010). }\end{array}$ & $\begin{array}{l}\text { CRSP, } \\
\text { Datastream, } \\
\text { IBES, EST }\end{array}$ & $\begin{array}{l}\text { Time-Varying } \\
\text { Updated monthly }\end{array}$ \\
\hline
\end{tabular}




\section{Table A.2: Summary Statistics of Main Variables}

This table provides summary statistics (i.e., means) for the main variables of our empirical study listed in Table A.1. Means are calculated for each country over all firms and all months. The sample covers multinational firms from 22 developed markets from June 2001 to December 2013.

\begin{tabular}{|c|c|c|c|c|c|c|c|c|c|}
\hline & (1) & (2) & (3) & (4) & (5) & (6) & (7) & (8) & (9) \\
\hline & Foreign_Info & Beta & Size & $\mathbf{B M}$ & $\mathbf{R}_{\mathrm{i}, \mathrm{t}-12: \mathrm{t}-2}$ & Turnover & Idio Vola & Dom_Ind_Ret & $\begin{array}{c}\text { Foreign_Info } \\
\text { Market }\end{array}$ \\
\hline Australia & $0.48 \%$ & 0.65 & 5.65 & 0.99 & $44.57 \%$ & $0.18 \%$ & 2.27 & $1.42 \%$ & $0.42 \%$ \\
\hline Austria & $0.48 \%$ & 0.72 & 6.75 & 2.30 & $18.06 \%$ & $0.09 \%$ & 0.88 & $1.49 \%$ & $0.49 \%$ \\
\hline Belgium & $0.59 \%$ & 0.73 & 6.22 & 0.91 & $11.15 \%$ & $0.09 \%$ & 0.69 & $1.27 \%$ & $0.51 \%$ \\
\hline Canada & $0.50 \%$ & 1.23 & 5.13 & 1.19 & $27.41 \%$ & $0.20 \%$ & 2.25 & $1.08 \%$ & $0.42 \%$ \\
\hline Denmark & $0.63 \%$ & 0.74 & 6.31 & 1.05 & $15.68 \%$ & $0.17 \%$ & 0.86 & $1.62 \%$ & $0.72 \%$ \\
\hline Finland & $0.53 \%$ & 0.53 & 6.14 & 0.86 & $15.17 \%$ & $0.19 \%$ & 0.76 & $1.39 \%$ & $0.62 \%$ \\
\hline France & $0.42 \%$ & 0.89 & 5.91 & 0.90 & $13.07 \%$ & $0.19 \%$ & 0.93 & $0.93 \%$ & $0.39 \%$ \\
\hline Germany & $0.40 \%$ & 0.73 & 5.83 & 0.88 & $14.03 \%$ & $0.16 \%$ & 1.06 & $1.07 \%$ & $0.90 \%$ \\
\hline Hong Kong & $0.50 \%$ & 1.03 & 5.55 & 1.67 & $29.97 \%$ & $0.29 \%$ & 1.71 & $1.35 \%$ & $0.36 \%$ \\
\hline Ireland & $0.55 \%$ & 0.91 & 7.36 & 1.13 & $14.30 \%$ & $0.13 \%$ & 0.96 & $1.22 \%$ & $0.48 \%$ \\
\hline Italy & $0.48 \%$ & 0.94 & 6.50 & 0.87 & $4.39 \%$ & $0.27 \%$ & 0.71 & $0.78 \%$ & $0.38 \%$ \\
\hline Japan & $0.27 \%$ & 1.05 & 6.12 & 1.22 & $11.32 \%$ & $0.41 \%$ & 0.81 & $0.46 \%$ & $0.20 \%$ \\
\hline Netherlands & $0.46 \%$ & 0.83 & 6.65 & 0.77 & $11.15 \%$ & $0.27 \%$ & 0.81 & $1.02 \%$ & $0.48 \%$ \\
\hline Norway & $0.56 \%$ & 0.92 & 6.26 & 0.97 & $18.29 \%$ & $0.30 \%$ & 1.03 & $1.52 \%$ & $0.58 \%$ \\
\hline New Zealand & $0.43 \%$ & 1.01 & 5.61 & 0.82 & $24.78 \%$ & $0.08 \%$ & 1.21 & $1.68 \%$ & $0.30 \%$ \\
\hline Portugal & $0.39 \%$ & 0.87 & 6.72 & 1.06 & $9.79 \%$ & $0.15 \%$ & 0.70 & $0.92 \%$ & $0.32 \%$ \\
\hline Singapore & $0.61 \%$ & 1.22 & 5.51 & 1.01 & $20.34 \%$ & $7.30 \%$ & 1.13 & $1.41 \%$ & $0.55 \%$ \\
\hline Spain & $0.39 \%$ & 0.84 & 7.41 & 0.72 & $11.47 \%$ & $0.30 \%$ & 0.67 & $1.11 \%$ & $0.33 \%$ \\
\hline Sweden & $0.58 \%$ & 0.90 & 5.89 & 0.75 & $16.38 \%$ & $0.24 \%$ & 0.90 & $1.67 \%$ & $0.66 \%$ \\
\hline Switzerland & $0.66 \%$ & 1.09 & 7.07 & 0.84 & $12.03 \%$ & $0.18 \%$ & 0.71 & $1.06 \%$ & $0.65 \%$ \\
\hline United Kingdom & $0.44 \%$ & 1.00 & 6.14 & 0.95 & $10.84 \%$ & $0.21 \%$ & 1.13 & $0.88 \%$ & $0.44 \%$ \\
\hline United States & $0.33 \%$ & 1.22 & 6.35 & 0.76 & $14.26 \%$ & $5.49 \%$ & 1.11 & $0.70 \%$ & $0.32 \%$ \\
\hline
\end{tabular}


Table A.2: Continued

\begin{tabular}{|c|c|c|c|c|c|c|c|}
\hline & (10) & (11) & (12) & (13) & (14) & (15) & (16) \\
\hline & Num_Analyst & Ownership & Num_Investors & $\begin{array}{l}\text { Geographical } \\
\text { Distance }\end{array}$ & Cultural Distance & $\begin{array}{l}\text { Sales Same } \\
\text { Language }\end{array}$ & $\mathbf{R}_{\mathbf{c}, \mathbf{t}}^{\mathbf{L S}}$ \\
\hline Australia & 4.61 & 0.03 & 10.88 & 5615.13 & 0.62 & 0,29 & $0.29 \%$ \\
\hline Austria & 4.66 & 0.07 & 11.21 & 1302.94 & 0.88 & 0.25 & $0.51 \%$ \\
\hline Belgium & 5.14 & 0.07 & 40.35 & 1700.82 & 0.71 & 0.22 & $1.09 \%$ \\
\hline Canada & 3.99 & 0.06 & 8.06 & 2093.63 & 0.36 & 0.12 & $0.02 \%$ \\
\hline Denmark & 5.69 & 0.10 & 23.41 & 1995.57 & 1.47 & 0.00 & $1.36 \%$ \\
\hline Finland & 7.28 & 0.15 & 14.97 & 2192.46 & 0.56 & 0.00 & $-0.20 \%$ \\
\hline France & 6.87 & 0.06 & 41.89 & 2057.32 & 0.77 & 0.28 & $0.31 \%$ \\
\hline Germany & 6.85 & 0.07 & 37.86 & 1990.33 & 0.41 & 0.27 & $0.16 \%$ \\
\hline Hong Kong & 5.40 & 0.03 & 13.05 & 3126.69 & 0.55 & 0.51 & $0.98 \%$ \\
\hline Ireland & 4.94 & 0.11 & 44.75 & 1676.86 & 0.41 & 0.41 & $1.78 \%$ \\
\hline Italy & 7.27 & 0.05 & 40.23 & 1621.66 & 0.37 & 0.00 & $0.06 \%$ \\
\hline Japan & 5.33 & 0.05 & 34.96 & 1944.19 & 0.67 & 0.00 & $0.78 \%$ \\
\hline Netherlands & 8.23 & 0.15 & 45.69 & 2068.02 & 1.04 & 0.02 & $0.50 \%$ \\
\hline Norway & 5.33 & 0.09 & 10.50 & 2847.27 & 1.17 & 0.00 & $0.36 \%$ \\
\hline New Zealand & 3.74 & 0.03 & 7.43 & 2759.01 & 0.18 & 0.31 & $0.25 \%$ \\
\hline Portugal & 5.74 & 0.04 & 62.27 & 1691.35 & 0.58 & 0.40 & $-0.02 \%$ \\
\hline Singapore & 4.49 & 0.03 & 8.55 & 3059.54 & 0.93 & 0.38 & $1.17 \%$ \\
\hline Spain & 11.14 & 0.07 & 98.65 & 1798.22 & 0.28 & 0.36 & $0.12 \%$ \\
\hline Sweden & 6.03 & 0.15 & 25.16 & 2178.48 & 1.26 & 0.00 & $0.19 \%$ \\
\hline Switzerland & 7.18 & 0.12 & 38.99 & 2863.71 & 0.51 & 0.18 & $1.20 \%$ \\
\hline United Kingdom & 4.05 & 0.13 & 35.37 & 2462.94 & 0.64 & 0.29 & $0.54 \%$ \\
\hline United States & 6.35 & 0.25 & 52.47 & 2827.08 & 0.48 & 0.15 & $0.52 \%$ \\
\hline
\end{tabular}


Table A.2: Continued

\begin{tabular}{|c|c|c|c|c|c|c|c|c|c|c|c|c|}
\hline & (17) & (18) & (19) & (20) & (21) & (22) & (23) & (24) & (25) & (26) & (27) & (28) \\
\hline & $\begin{array}{c}\text { Local } \\
\text { Market } \\
\text { Return } \\
\end{array}$ & $\begin{array}{c}\text { Local } \\
\text { Market } \\
\text { Volatility }\end{array}$ & $\begin{array}{c}\text { Domestic } \\
\text { Bias }\end{array}$ & $\begin{array}{l}\text { Foreign } \\
\text { Bias }\end{array}$ & Schooling & Trust & PEAD & $\begin{array}{c}\text { Segmen- } \\
\text { tation }\end{array}$ & $\begin{array}{c}\text { Capital } \\
\text { Flow } \\
\text { Restrictions } \\
\end{array}$ & $\begin{array}{l}\text { Credit } \\
\text { Rating }\end{array}$ & $\begin{array}{c}\text { Turnover } \\
\text { Ratio }\end{array}$ & Trading \\
\hline Australia & $0.77 \%$ & $3.21 \%$ & 3.94 & -1.23 & 10.57 & - & $3.58 \%$ & 2.4 & 8 & 75.8 & 48.16 & 45.16 \\
\hline Austria & $0.35 \%$ & $4.38 \%$ & 4.28 & -1.79 & 8.79 & 0.32 & $1.22 \%$ & 2.2 & 8 & 89.4 & 49.52 & 6.71 \\
\hline Belgium & $0.32 \%$ & $4.27 \%$ & 3.77 & -2.26 & 8.73 & 0.34 & $2.01 \%$ & 3.1 & 10 & 84.9 & 24.68 & 16.83 \\
\hline Canada & $0.95 \%$ & $4.41 \%$ & 2.41 & -2.53 & 11.43 & 0.53 & $0.97 \%$ & 2.7 & 10 & 83.5 & 65.64 & 57.86 \\
\hline Denmark & $0.88 \%$ & $4.08 \%$ & 4.07 & -1.03 & 10.09 & 0.58 & $2.73 \%$ & 3.4 & 10 & 85.1 & 64.23 & 36.27 \\
\hline Finland & $-0.15 \%$ & $4.56 \%$ & 3.86 & 0.06 & 10.14 & 0.63 & $4.81 \%$ & 4.5 & 8 & 83.6 & 51.34 & 70.97 \\
\hline France & $0.44 \%$ & $3.53 \%$ & 2.55 & -0.44 & 8.38 & 0.23 & $2.30 \%$ & 2.9 & 5 & 91.4 & 63.82 & 44.9 \\
\hline Germany & $0.94 \%$ & $2.98 \%$ & 2.12 & -0.65 & 9.75 & 0.38 & $-1.34 \%$ & 2.5 & 10 & 92 & 118.46 & 37.8 \\
\hline Hong Kong & $0.78 \%$ & $3.74 \%$ & 2.66 & -1.54 & 9.46 & - & $5.13 \%$ & - & 10 & 61.3 & 64.94 & 179.05 \\
\hline Ireland & $0.43 \%$ & $4.95 \%$ & 3.06 & -0.97 & 9.02 & 0.47 & $2.91 \%$ & 4.2 & 8 & 83.4 & 59.96 & 30.79 \\
\hline Italy & $0.78 \%$ & $3.31 \%$ & 2.77 & -1.20 & 7.00 & 0.35 & $-2.73 \%$ & 2.2 & 10 & 81.3 & 80.08 & 36.58 \\
\hline Japan & $0.15 \%$ & $3.20 \%$ & 1.86 & -0.97 & 9.72 & 0.42 & $3.47 \%$ & 2.8 & 8 & 86.5 & 49.4 & 35.5 \\
\hline Netherlands & $0.04 \%$ & $4.81 \%$ & 2.27 & -0.35 & 9.24 & 0.53 & $1.33 \%$ & 3.1 & 10 & 91.2 & 95.36 & 113.49 \\
\hline Norway & $0.49 \%$ & $4.29 \%$ & 7.00 & -2.38 & 11.52 & - & $1.81 \%$ & 3.2 & 8 & 74 & 42.68 & 17.82 \\
\hline New Zealand & $-0.15 \%$ & $3.42 \%$ & 5.55 & -1.71 & 11.86 & 0.65 & $3.11 \%$ & 6 & 8 & 87.7 & 79.64 & 30.15 \\
\hline Portugal & $0.47 \%$ & $4.65 \%$ & 5.48 & -1.56 & 4.91 & 0.22 & $2.72 \%$ & 2.3 & 8 & 78.4 & 68.18 & 30.98 \\
\hline Singapore & $0.23 \%$ & $3.10 \%$ & 3.55 & -0.85 & 8.12 & - & $2.95 \%$ & 2.9 & 10 & 81.9 & 49.62 & 79.15 \\
\hline Spain & $0.49 \%$ & $3.94 \%$ & 3.22 & -0.72 & 7.25 & 0.34 & $1.09 \%$ & 2.5 & 8 & 81.7 & 174.82 & 107.98 \\
\hline Sweden & $0.83 \%$ & $4.27 \%$ & 3.81 & -0.41 & 11.36 & 0.66 & $-0.04 \%$ & 3.1 & 10 & 81.2 & 78.08 & 92.22 \\
\hline Switzerland & $0.45 \%$ & $4.10 \%$ & 2.26 & -0.6 & 10.39 & 0.43 & $1.12 \%$ & 2.4 & 10 & 93 & 91.22 & 206.27 \\
\hline United Kingdom & $0.40 \%$ & $3.04 \%$ & 1.67 & -0.41 & 9.35 & 0.44 & $1.81 \%$ & 2.3 & 10 & 90.2 & 50.62 & 83.02 \\
\hline United States & $0.27 \%$ & $3.06 \%$ & 0.61 & -1.43 & 12.25 & 0.51 & $2.60 \%$ & 1.2 & 10 & 90.9 & 125.3 & 178.88 \\
\hline
\end{tabular}




\section{Table A.3: Google Trends Search Terms}

This table provides the detailed search terms for the Google Trends analysis in Section 5.2. The search request is performed by the exact name of the main stock market index as shown in the table.

\begin{tabular}{lc}
\hline & Search Term \\
\hline Australia & S\&P/ASX 200 \\
Austria & ATX \\
Belgium & BEL20 \\
Canada & S\&P/TSX 60 \\
Denmark & OMX Copenhagen Index \\
Finland & OMX Helsinki 25 \\
France & CAC 40 \\
Germany & DAX 30 \\
Hong Kong & Hang Seng Index \\
Ireland & ISE \\
Italy & FTSE MIB \\
Japan & NIKKEI 225 \\
Netherlands & AEX \\
Norway & OSE \\
New Zealand & NZX 50 \\
Portugal & PSI 20 \\
Singapore & STI Index \\
Spain & IBEX 35 \\
Sweden & Straits Times Index \\
Switzerland & SMI \\
United Kingdom & S\&P 500 100 \\
United States & \\
\hline & \\
\hline
\end{tabular}




\section{A.4: Relationship between the Foreign Information Effect and the Business Cycle}

This section investigates whether the magnitude of the Foreign_Info returns spread across individual countries varies over the business cycle. This analysis is motivated by recent studies of Hou et al. (2009), Karlsson et al. (2009), Sicherman et al. (2015), and Jacobs and Weber (2015) who find that that investor attention is related to economic conditions and that stock market participants generally pay less attention to value-relevant information during recessions. We regress $R_{c, t}^{L S}$ on the same explanatory variables as in Equation (7) in Section 5.2 and add country c's local recession dummy in the previous month, $L B C_{c, t-1}$, and a global recession dummy, $G B C_{t-1}$, to the regressors. ${ }^{43}$ Hence, we estimate

$$
\begin{aligned}
R_{c, t}^{L S} & =\beta_{0}+\beta_{1, \mathrm{c}}+\beta_{2} A S V I_{c, t-1}+\beta_{3} L B C_{c, t-1}+\beta_{4} G B C_{t-1} \\
& +\beta_{5}^{\prime} V_{c, t-1}+\beta_{6}^{\prime} W_{c, t}+\varepsilon_{c, t} .
\end{aligned}
$$

Specifications (1) and (2) of Table A.4 report the relationship between the Foreign_Info return spread and the recession indicators. In both specifications, we find that the Foreign_Info effect is significantly larger during recession periods. Specifications (3) - (5) report the results using business cycle dummies and the Google Trends measures for investor attention (i.e. Domestic_ASVI and Foreign_ASVI) in a joint model. Our results indicate that the only significant variable affecting the Foreign_Info return spread is Foreign_ASVI, while the impact of the respective recession indicator becomes insignificant.

\footnotetext{
${ }^{43}$ To measure domestic business cycle variation, we use the recession indicator for the United States from the National Bureau of Economic Research (NBER) and recession indicators for the non-U.S. countries in our sample from the Organisation for Economic Co-operation and Development (OECD). We also obtain data for the recession indicator of the total OECD area to measure global business cycle variation.
} 


\section{Table A.4: The Foreign Information Effect and the Business Cycle}

This table reports the results of OLS-regressions of country $c$ 's Foreign_Info return spread in month $t$ on country $c$ 's measures of investor attention and business cycle variables in month $t-1 . R_{c, t}^{L S}$ denotes country c's Foreign_Info return spread in month $t, A S V I_{c, t-1}$ denotes one of the abnormal attention measure of individuals in country $c$ in month $t$ - 1 , and $L B C_{c, t-1}$ and $G B C_{t-1}$ denote the local and global recession indicators at month $t$ - 1 . We also control for different country characteristics (Size, Num_Analyst, Ownership, Num_Investors, as defined in Section 5.1) measured at month $t-1$, as well as the local market return and market volatility (computed as the past 36 months rolling standard deviation of the market return) at month $t$. We perform the OLS regression including country-fixed effects and Newey-West standard errors. Columns (1) and (2) investigate the relationship between the magnitude of the Foreign_Info return spread and local and global recession indicators. Columns (3) - (5) report the results when using both investor attention variables and the local, the global or both business cycle dummies in a joint model. Tstatistics are calculated using the Newey and West (1987) method with 12 lags.*,** and *** denote statistical significance at the $10 \%, 5 \%$ and $1 \%$ level, respectively. The sample covers multinational firms from 22 developed markets from 2004 to 2013.

\begin{tabular}{|c|c|c|c|c|c|}
\hline & (1) & (2) & (3) & (4) & (5) \\
\hline & \multicolumn{2}{|c|}{ Recession Indicators } & \multicolumn{3}{|c|}{ All Variables } \\
\hline & $R_{C+}^{L S}$ & $R_{C+}^{L S}$ & $R_{C+}^{L S}$ & $R_{c t}^{L S}$ & $R_{C+}^{L S}$ \\
\hline Domestic_ASVI $I_{c, t-1}$ & & & $\begin{array}{c}0.00122 \\
(0.23)\end{array}$ & $\begin{array}{c}0.00120 \\
(0.25)\end{array}$ & $\begin{array}{c}0.00113 \\
(0.21)\end{array}$ \\
\hline Foreign_ASVI $I_{c, t-1}$ & & & $\begin{array}{c}-0.00936 * * \\
(-2.14)\end{array}$ & $\begin{array}{c}-0.00926 * * \\
(-2.18)\end{array}$ & $\begin{array}{c}-0.00932 * * \\
(-2.13)\end{array}$ \\
\hline$L B C_{c, t-1}$ & $\begin{array}{c}0.00388^{*} \\
(1.65)\end{array}$ & & $\begin{array}{c}0.00339 \\
(1.27)\end{array}$ & & $\begin{array}{c}0.00153 \\
(0.46)\end{array}$ \\
\hline$G B C_{t-1}$ & & $\begin{array}{c}0.00454 * \\
(1.76)\end{array}$ & & $\begin{array}{c}0.00449 \\
(1.41)\end{array}$ & $\begin{array}{c}0.00348 \\
(0.82)\end{array}$ \\
\hline Additional Controls & Yes & Yes & Yes & Yes & Yes \\
\hline Constant & $\begin{array}{c}0.00589 \\
(1.31)\end{array}$ & $\begin{array}{c}0.00781 * * * \\
(1.90)\end{array}$ & $\begin{array}{c}0.00371 \\
(0.73)\end{array}$ & $\begin{array}{c}0.00560 \\
(1.22)\end{array}$ & $\begin{array}{c}0.00356 \\
(0.69)\end{array}$ \\
\hline $\mathrm{N}$ & 2,980 & 3,278 & 2,445 & 2,595 & 2,445 \\
\hline R2 & 0.015 & 0.015 & 0.023 & 0.023 & 0.024 \\
\hline
\end{tabular}




\section{A.5: Business Cycle Measures and Investor Attention}

The results in columns (1) and (2) of Table A.4 show that the return spread due to Foreign_Info is significantly higher during times of economic downturns; however, statistical significance of these results vanishes when we take into account measures of investor attention in models (3) - (5). These patterns point to an interesting relationship between business cycle dynamics and investor attention. To take a closer look at the relationship, we regress the respective business cycle dummy on measures of investor attention, using the same set of controls as in Equation (7) in Section 5.2

$$
B C_{c, t}=\beta_{0}+\beta_{1, \mathrm{c}}+\beta_{2} A S V I_{c, t}+\beta_{3}^{\prime} V_{c, t-1}+\beta_{4}^{\prime} W_{c, t}+\varepsilon_{c, t}
$$

We again estimate Equation (10) using Ordinary Least Squares including country-fixed effects and Newey-West clustered standard errors. Results are shown in Table A.5. In specification (1), we look at the correlation between the recession dummy and overall attention of investors. We find a slightly negative but statistically insignificant coefficient documenting that individuals slightly decrease their attention to overall financial information during bad states of the economy (in line with the findings of Sicherman et al., 2015). More interestingly in our context, we then separate overall attention into domestic and foreign attention in specification (2). Our results show that the recession dummy is significantly positively correlated with attention to Domestic_ASVI, while it is significantly negatively correlated to Foreign_ASVI. These results indicate that, during recessions, investors increase attention to domestic financial information and decrease attention to foreign financial information. If attention is a limited cognitive resource (e.g., Kahneman, 1973; Cohen and Frazzini, 2008), an increase in the amount of domestic attention potentially limits investors' capabilities to observe foreign information. Hence, during times of economic downturns, investor attention to domestic information appears to crowd out 
attention to foreign information. Specifications (3) and (4) repeat specifications (1) and (2) with the global recession indicator as the dependent variable and yield almost identical results. ${ }^{44}$

Our findings are important for the academic literature on investor attention and business cycle variation. We contribute by demonstrating that attention to domestic financial information crowds out attention to foreign financial information during times of economic downturns.

\section{Table A.5: Investor Attention in Recessions}

This table report the results of OLS-regressions of the respective business cycle dummy in month $t$ on measures of attention at month $t$, again controlling for different country characteristics in month $t-1$ as well as the local market return and market volatility (computed as the past 36 months rolling standard deviation of the market return) in month $t$. We again perform the OLS regression including country-fixed effects and Newey-West clustered standard errors. In column (1), we look at the relationship between the recession dummy and overall attention of investors. We then separate overall attention into domestic and foreign attention in column (2). Columns (3) and (4) repeat columns (1) and (2) with global recession as the dependent variable. T-statistics are calculated using the Newey and West (1987) method with 12 lags. *** and *** denote statistical significance at the $10 \%, 5 \%$ and $1 \%$ level, respectively. The sample covers multinational firms from 22 developed markets from 2004 to 2013.

\begin{tabular}{|c|c|c|c|c|}
\hline & \multicolumn{2}{|c|}{ Local Recession } & \multicolumn{2}{|c|}{ Global Recession } \\
\hline & (1) & (2) & (3) & (4) \\
\hline & $L B C_{c t}$ & $L B C_{c t}$ & $G B C_{t}$ & $G B C_{t}$ \\
\hline Overall_ASVI $I_{c, t}$ & $\begin{array}{c}-0.000652 \\
(-0.57)\end{array}$ & & $\begin{array}{c}-0.00105 \\
(-1.05)\end{array}$ & \\
\hline Domestic_ASVI $I_{c, t}$ & & $\begin{array}{c}0.00378^{* * *} \\
(1.97)\end{array}$ & & $\begin{array}{c}0.00334 * * \\
(2.10)\end{array}$ \\
\hline Foreign_ASVI I $I_{c, t}$ & & $\begin{array}{c}-0.00468 * * * * \\
(-2.80)\end{array}$ & & $\begin{array}{c}-0.00522 \text { *** } \\
(-3.99)\end{array}$ \\
\hline Additional Controls & Yes & Yes & Yes & Yes \\
\hline Constant & $\begin{array}{c}0.385^{* * * *} \\
(3.03)\end{array}$ & $\begin{array}{c}0.410 * * * \\
(3.35)\end{array}$ & $\begin{array}{c}0.298 * * * \\
(2.75)\end{array}$ & $\begin{array}{c}0.318 * * * \\
(3.04)\end{array}$ \\
\hline $\mathrm{N}$ & 2,400 & 2,400 & 2,640 & 2,640 \\
\hline R2 & 0.051 & 0.068 & 0.027 & 0.048 \\
\hline
\end{tabular}

\footnotetext{
${ }^{44}$ In unreported results, we also repeat regression specifications (2) and (4) of Table A.5 for the 22 individual countries in our sample. The relationship between the recession dummy and Domestic_ASVI is positive in 17 (15) of 22 countries and the relationship between the recession dummy and Foreign_ASVI is negative in 16 (16) of 22 countries. The results are available upon request.
} 


\section{References}

Addoum, J.M., Kumar, A., and Law, K. (2015) Slow Diffusion of State-Level Information and Return Predictability, unpublished working paper, University of Miami.

Ang, A., Hodrick, R.J., Xing, Y., and Zhang, X. (2006) The Cross-Section of Volatility and Expected Returns, Journal of Finance 61, 259-299.

Ang, A., Hodrick, R.J., Xing, Y., and Zhang, X. (2009) High idiosyncratic volatility and low returns: International and further U.S. evidence, Journal of Financial Economics 91, 1-23.

Arbel, A., Carvell, S., and Strebel, P. (1983) Giraffes, Institutions and Neglected Firms, Financial Analyst Journal 39, 57-63.

Asness, C.S., Frazzini, A., and Pedersen, L.H. (2014), Quality Minus Junk, unpublished working paper, AQR Capital Management.

Badrinath, S.G., Kale, J.R., and Noe, T.H. (1995) On Shephards, Sheep and the Cross-autocorrelations in Equity Returns, Review of Financial Studies 8, 401-430.

Banz, R.W. (1981) The relationship between return and market value of common stocks, Journal of Financial Economics 9, 3-18.

Barro, R.J., and Lee, J.W. (2013) A new data set of educational attainment in the world, 1950-2010, Journal of Development Economics 104, 184-198.

Basu, S. (1983) The relationship between earnings' yield, market value and return for NYSE common stocks: Further evidence, Journal of Financial Economics 12, 129-156.

Bekaert, G., Harvey, C.R., Lundblad, C.T., and Siegel, S. (2011) What Segments Equity Markets? Review of Financial Studies 24, 3841-3890.

Boehmer, E., and Kelley, E.K. (2009) Institutional Investors and the Informational Efficiency of Prices, Review of Financial Studies 22, 3563-3594.

Brennan, M.J., Jegadeesh, N., and Swaminathan, B. (1993) Investment Analysis and the Adjustment of Stock Prices to Common Information, Review of Financial Studies 6, 799-824.

Bushan, R. (1989) Firm characteristics and analyst following, Journal of Accounting and Economics 11, 255-274.

Cao, J., Chordia, T., and Lin, C. (2015) Alliances and Return Predictability, Journal of Financial and Quantitative Analysis, forthcoming. 
Carhart, M.M. (1997) On Persistence in Mutual Fund Performance, Journal of Finance 52, 57-82.

Chan, K., Covrig, V., and Ng, L. (2005) What Determines the Domestic Bias and Foreign Bias? Evidence from Mutual Fund Equity Allocations Worldwide, Journal of Finance 60, 1495-1534.

Cohen, L., and Frazzini, A. (2008) Economic Links and Predictable Returns, Journal of Finance 63, 19772011.

Cohen, L., and Lou, D. (2012) Complicated firms, Journal of Financial Economics 104, 383-400.

Da, Z., Engelberg, J., and Gao, P. (2011) In Search of Attention, Journal of Finance 66, 1461-1499.

Da, Z., Engelberg, J., and Gao, P. (2014) The Sum of All FEARS: Investor Sentiment and Asset Prices, Review of Financial Studies, forthcoming.

De Long, J.B., Shleifer, A., Summers, L.H., and Waldmann, R.J. (1990) Noise Trader Risk in Financial Markets, Journal of Political Economy 98, 703-738.

Denis, D.J., Denis, D.K., and Yost, K. (2002) Global Diversification, Industrial Diversification, and Firm Value, Journal of Finance 57, 1951-1979.

Dimpfl, T., and Jank, S. (2016) Can Internet Search Queries Help to Predict Stock Market Volatility?, European Financial Management 22, 171-192.

Duffie, D. (2010) Presidential Address: Asset Price Dynamics with Slow-Moving Capital, Journal of Finance 65, 1237-1267.

Fama, E.F., and French, K.R. (1992) The Cross-Section of Expected Stock Returns, Journal of Finance $47,472-465$.

Fama, E.F., and French, K.R. (1993) Common Risk Factors in the Returns on Stocks and Bonds, Journal of Financial Economics 33, 3-56.

Fama, E.F., and French, K.R. (2012) Size, value, and momentum in international stock returns, Journal of Financial Economics 105, 457-472.

Fama, E.F., and French, K.R. (2015a) A five-factor asset pricing model, Journal of Financial Economics $116,1-22$.

Fama, E.F., and French, K.R. (2015b) International tests of a five-factor asset pricing model, unpublished working paper, University of Chicago. 
Fama, E.F., and MacBeth, J.D. (1973) Risk, Return, and Equilibrium: Empirical Tests, Journal of Political Economy 81, 607-636.

Griffin, J.M. (2002) Are the Fama and French Factors Global or Country Specific?, Review of Financial Studies 15, 783-803.

Griffin, J.M., Kelly, P.J., and Nardari, F. (2010) Do Market Efficiency Measures Yield Correct Inferences? A Comparison of Developed and Emerging Markets, Review of Financial Studies 23, 3225-3277.

Grinblatt, M., and Moskowitz, T.J. (1999) Do Industries Explain Momentum?, Journal of Finance 54, 1249-1290.

Grossmann, S.J., and Stiglitz, J.E. (1980) On the Impossibility of Informationally Efficient Markets, American Economic Review 70, 393-408.

Guiso, L., Sapienza, P., and Zingales, L. (2008) Trusting the Stock Market, Journal of Finance 63, 25572600 .

Hau, H., and Lai, S. (2014) The Role of Equity Funds in the Financial Crisis Propagation, unpublished working paper, University of Geneva.

Hofstede, G., Hofstede, G.J., and Minkov, M. (2010) Cultures and Organizations: Software of the Mind, Mcgraw-Hill, New York.

Hong, H., Lim, T., and Stein, J.C. (2000) Bad News Travels Slowly: Size, Analyst Coverage, and the Profitability of Momentum Strategies, Journal of Finance 55, 265-295.

Hong, H., and Stein, J.C. (2007) Disargreement and the Stock Market, Journal of Economic Perspectives $21,109-128$.

Hou, K. (2007) Industry Information Diffusion and the Lead-lag Effect in Stock Returns, Review of Financial Studies 27, 1113-1138.

Hou, K., and Moskowitz, T.J. (2005) Market Frictions, Price Delay, and the Cross-Section of Expected Returns, Review of Financial Studies 18, 981-1020.

Hou, K., Xiong, W., and Peng, L. (2009) A Tale of Two Anomalies: The Implications of Investor Attention for Price and Earnings Momentum, unpublished working paper, Ohio State University.

Huang, X. (2015) Thinking Outside the Borders: Investors' Inattention to Foreign Operations, Review of Financial Studies, forthcoming. 
Ibbotson, R.G., Chen, Z., Kim, D.Y.-J., and Hu, W.Y. (2013) Liquidity as an Investment Style, Financial Analyst Journal 69, 30-44.

Ince, O.S., and Porter, R.B. (2006) Individual Equity Return Data from Thomson Datastream: Handle with Care!, Journal of Financial Research 29, 463-479.

Jacobs, H., and Weber, M. (2015) On the Determinants of Pairs Trading Profitability, Journal of Financial Markets forthcoming.

Jegadeesh, N. (1990) Evidence of Predictable Behavior of Security Returns, Journal of Finance 45, 881898.

Jegadeesh, N., and Titman, S. (1993) Returns to Buying Winners and Selling Losers: Implications for Stock Market Efficiency, Journal of Finance 48, 65-91.

Kahneman, D. (1973) Attention and Effort, Prentice Hall, New Jersey.

Karlsson, N., Loewenstein, G., and Seppi, D. (2009) The ostrich effect: Selective attention to information, Journal of Risk and Uncertainty 38, 95-115.

Kogut, B., and Singh, H. (1988) The Effect of National Culture on the Choice of Entry Mode, International Business Studies 19, 411-432.

La Porta, R., Lopez-De-Silanes, F., and Shleifer, A. (2006) What Works in Securities Laws?, Journal of Finance 61, 1-32.

Lintner, J. (1965) The Valuation of Risk Assets and the Selection of Risky Investments in Stock Portfolios and Capital Budgets, Review of Economics and Statistics 47, 13-37.

Lo, A.W., and MacKinlay, A.C. (1990) When are Contrarian Profits Due to Stock Market Overreaction?, Review of Financial Studies 3, 175-205.

Menzly, L., and Ozbas, O. (2010) Market Segmentation and Cross-predictability of Returns, Journal of Finance 65, 1555-1580.

Merton, R.C. (1987) A Simple Model of Capital Market Equilibrium with Incomplete Information, Journal of Finance 42, 483-510.

Newey, W.K., and West, K.D. (1987) A Simple, Positive Semi-Definite, Heteroskedasticity and Autocorrelation Consistent Covariance Matrix, Econometrica 55, 703-708.

Nguyen, Q.H. (2012) Geographic Momentum, unpublished working paper, University of Illinois. 
Nijman, T., Swinkels, L., and Verbeek, M. (2004) Do countries or industries explain momentum in Europe?, Journal of Empirical Finance 11, 461-481.

Pontiff, J. (2006) Costly arbitrage and the myth of idiosyncratic risk, Journal of Accounting and Economics 42, 35-52.

Rizova, S. (2013) Trade Momentum. Journal of International Financial Markets, Institutions and Money 24, 258-293.

Rouwenhorst, K.G. (1999) Local Return Factors and Turnover in Emerging Stock Markets, Journal of Finance 54, 1439-1464.

Sharpe, W. (1964) Capital Asset Prices: A Theory of Market Equilibrium under Conditions of Risk, Journal of Finance 19, 425-442.

Shleifer, A. (2009) The Age of Milton Friedman, Journal of Economic Literature 47, 123-135.

Shleifer, A., and Vishny, R.W. (1997) The Limits of Arbitrage, Journal of Finance 52, 35-55.

Sicherman, N., Loewenstein, G., Seppi, D.J. and Utkus, S. (2015) Financial Attention, unpublished working paper, Columbia University.

Smajlbegovic, E. (2016) Regional Economic Activity and Stock Returns, unpublished working paper, Erasmus University of Rotterdam.

Stambaugh, R.F., Yu, J., and Yuan, Y. (2015) Arbitrage Asymmetry and the Idiosyncratic Volatility Puzzle, Journal of Finance 70, 1903-1948. 


\section{Table 1: Summary Statistics}

This table presents summary statistics for the sample used in this paper. Data for U.S. multinationals are from CRSP and Compustat. Data for non-U.S. multinationals are from Datastream and Worldscope. We assign each individual country to one of three regions: Asia-Pacific, Europe and North America. Panel A reports summary statistics for all countries in the sample. Foreign_Info is the geographic sales weighted average of foreign industry returns from a multinational firm's foreign segments. Total Share Foreign Sales is the average cumulated foreign sales of all multinational firms divided by cumulated total sales. Panel B reports geographic sales statistics of all countries in the sample. Column (1) show the average Herfindahl index of the geographic sales of all multinational firms in the respective country. Columns (2) to (5) report the sales of all multinational firms with respect to individual regions, where the regions are defined as in Panel A. Columns (6) to (12) report the top three countries with the highest share of foreign sales. The sample covers multinational firms from 22 developed markets from June 2001 to December 2013.

Panel A: Firm Characteristics

\begin{tabular}{|c|c|c|c|c|c|c|c|c|c|}
\hline & (1) & (2) & (3) & (4) & (5) & (6) & (7) & (8) & (9) \\
\hline & Asia- & Furene & North & No Firms & Firm Month & Total Share & \multicolumn{3}{|c|}{ Foreign Info } \\
\hline & Pacific & Non & America & 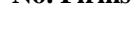 & Observations & Foreign Sales & Min & Mean & Max \\
\hline Australia & $\mathrm{x}$ & & & 829 & 24,305 & $27.65 \%$ & $-33.65 \%$ & $0.48 \%$ & $41.57 \%$ \\
\hline Austria & & $\mathrm{x}$ & & 92 & 3,995 & $47.65 \%$ & $-35.26 \%$ & $0.48 \%$ & $26.47 \%$ \\
\hline Belgium & & $\mathrm{x}$ & & 117 & 5,546 & $42.44 \%$ & $-28.24 \%$ & $0.59 \%$ & $30.28 \%$ \\
\hline Canada & & & $\mathrm{x}$ & 1,144 & 39,130 & $39.23 \%$ & $-33.93 \%$ & $0.50 \%$ & $26.75 \%$ \\
\hline Denmark & & $\mathrm{x}$ & & 129 & 5,975 & $56.09 \%$ & $-27.72 \%$ & $0.63 \%$ & $30.21 \%$ \\
\hline Finland & & $\mathrm{x}$ & & 132 & 8,221 & $65.87 \%$ & $-29.20 \%$ & $0.53 \%$ & $46.39 \%$ \\
\hline France & & $\mathrm{x}$ & & 601 & 35,380 & $48.46 \%$ & $-28.46 \%$ & $0.42 \%$ & $31.57 \%$ \\
\hline Germany & & $\mathrm{x}$ & & 620 & 28,999 & $50.41 \%$ & $-30.99 \%$ & $0.40 \%$ & $25.66 \%$ \\
\hline Hong Kong & $\mathrm{x}$ & & & 1,041 & 45,369 & $44.71 \%$ & $-34.21 \%$ & $0.50 \%$ & $45.00 \%$ \\
\hline Ireland & & $\mathrm{x}$ & & 55 & 1,966 & $62.38 \%$ & $-21.91 \%$ & $0.55 \%$ & $23.63 \%$ \\
\hline Italy & & $\mathrm{x}$ & & 247 & 14,807 & $38.30 \%$ & $-27.02 \%$ & $0.48 \%$ & $25.27 \%$ \\
\hline Japan & $\mathrm{x}$ & & & 1,424 & 105,379 & $25.26 \%$ & $-22.40 \%$ & $0.27 \%$ & $27.59 \%$ \\
\hline Netherlands & & $\mathrm{x}$ & & 163 & 10,031 & $63.04 \%$ & $-29.73 \%$ & $0.46 \%$ & $24.64 \%$ \\
\hline Norway & & $\mathrm{x}$ & & 186 & 6,215 & $42.33 \%$ & $-29.21 \%$ & $0.56 \%$ & $33.49 \%$ \\
\hline New Zealand & $\mathrm{x}$ & & & 94 & 3,042 & $30.40 \%$ & $-23.99 \%$ & $0.43 \%$ & $17.27 \%$ \\
\hline Portugal & & $\mathrm{x}$ & & 41 & 2,389 & $32.69 \%$ & $-22.07 \%$ & $0.39 \%$ & $19.37 \%$ \\
\hline Singapore & $\mathrm{x}$ & & & 638 & 23,002 & $53.94 \%$ & $-42.78 \%$ & $0.61 \%$ & $31.76 \%$ \\
\hline Spain & & $\mathrm{x}$ & & 131 & 8,573 & $39.74 \%$ & $-23.83 \%$ & $0.39 \%$ & $26.91 \%$ \\
\hline Sweden & & $\mathrm{x}$ & & 314 & 15,574 & $59.33 \%$ & $-33.98 \%$ & $0.58 \%$ & $35.72 \%$ \\
\hline Switzerland & & $\mathrm{x}$ & & 222 & 14,347 & $61.48 \%$ & $-30.96 \%$ & $0.66 \%$ & $33.06 \%$ \\
\hline United Kingdom & & $\mathrm{x}$ & & 1,724 & 53,357 & $42.68 \%$ & $-38.15 \%$ & $0.44 \%$ & $30.68 \%$ \\
\hline United States & & & $\mathrm{x}$ & 3,314 & 210,943 & $43.39 \%$ & $-28.80 \%$ & $0.33 \%$ & $24.97 \%$ \\
\hline Total & 5 & 15 & 2 & 13,258 & 666,545 & $46.25 \%$ & $-42.78 \%$ & $0.48 \%$ & $46.39 \%$ \\
\hline
\end{tabular}


Panel B: Foreign Sales Summary Statistics

\begin{tabular}{|c|c|c|c|c|c|c|c|c|c|c|c|c|}
\hline & (1) & (2) & (3) & (4) & $(5)$ & (6) & (7) & $(8)$ & (9) & (10) & (11) & (12) \\
\hline & & \multicolumn{4}{|c|}{ Sales According to Region } & \multicolumn{7}{|c|}{ Top 3 Foreign Sales Countries } \\
\hline & Herfindahl & Asia-Pacific & Europe & $\begin{array}{c}\text { North } \\
\text { America }\end{array}$ & Other & \multicolumn{2}{|c|}{ Top 1} & & & \multicolumn{2}{|c|}{ Top 3} & Sum \\
\hline Australia & 0.67 & $54.5 \%$ & $18.4 \%$ & $13.3 \%$ & $13.9 \%$ & New Zealand & $13.4 \%$ & USA & $8,2 \%$ & China & $6.1 \%$ & $27.7 \%$ \\
\hline Austria & 0.46 & $3.3 \%$ & $75.4 \%$ & $2.4 \%$ & $18.9 \%$ & Germany & $15.0 \%$ & $\begin{array}{c}\text { Czech } \\
\text { Republic }\end{array}$ & $4.3 \%$ & Turkey & $2.9 \%$ & $22.1 \%$ \\
\hline Belgium & 0.48 & $8.8 \%$ & $48.9 \%$ & $28.1 \%$ & $14.3 \%$ & USA & $14.4 \%$ & France & $5.0 \%$ & Netherlands & $3.8 \%$ & $23.2 \%$ \\
\hline Canada & 0.61 & $9.7 \%$ & $24.4 \%$ & $49.2 \%$ & $16.7 \%$ & USA & $43.9 \%$ & $\begin{array}{l}\text { United } \\
\text { Kingdom }\end{array}$ & $4.1 \%$ & Australia & $1.0 \%$ & $56.0 \%$ \\
\hline Denmark & 0.49 & $8.1 \%$ & $67.1 \%$ & $13.1 \%$ & $11.7 \%$ & Germany & $9.9 \%$ & Sweden & $3.2 \%$ & Norway & $2.0 \%$ & $15.1 \%$ \\
\hline Finland & 0.44 & $12.7 \%$ & $63.2 \%$ & $12.1 \%$ & $11.9 \%$ & Sweden & $8.4 \%$ & Germany & $6.2 \%$ & China & $5.9 \%$ & $20.5 \%$ \\
\hline France & 0.50 & $8.6 \%$ & $65.7 \%$ & $16.2 \%$ & $9.5 \%$ & Germany & $12.3 \%$ & USA & $7.6 \%$ & $\begin{array}{l}\text { United } \\
\text { Kingdom }\end{array}$ & $2.8 \%$ & $22.6 \%$ \\
\hline Germany & 0.49 & $14.3 \%$ & $47.1 \%$ & $24.7 \%$ & $13.9 \%$ & USA & $18.3 \%$ & France & $14.3 \%$ & $\begin{array}{c}\text { United } \\
\text { Kingdom }\end{array}$ & $4.6 \%$ & $37.3 \%$ \\
\hline Hong Kong & 0.63 & $76.8 \%$ & $10.6 \%$ & $9.1 \%$ & $3.4 \%$ & China & $54.2 \%$ & USA & $6.9 \%$ & Singapore & $1.5 \%$ & $62.5 \%$ \\
\hline Ireland & 0.56 & $2.1 \%$ & $68.3 \%$ & $22.0 \%$ & $7.5 \%$ & $\begin{array}{l}\text { United } \\
\text { Kingdom }\end{array}$ & $18.3 \%$ & USA & $12.3 \%$ & Netherlands & $3.3 \%$ & $33.9 \%$ \\
\hline Italy & 0.49 & $4.3 \%$ & $62.4 \%$ & $20.1 \%$ & $13.3 \%$ & Germany & $16.3 \%$ & France & $13.5 \%$ & USA & $10.9 \%$ & $40.7 \%$ \\
\hline Japan & 0.62 & $28.4 \%$ & $22.6 \%$ & $37.1 \%$ & $11.9 \%$ & USA & $27.8 \%$ & China & $8.4 \%$ & Australia & $3.5 \%$ & $39.7 \%$ \\
\hline Netherlands & 0.45 & $12.8 \%$ & $43.8 \%$ & $34.5 \%$ & $8.9 \%$ & USA & $21.0 \%$ & Germany & $14.6 \%$ & $\begin{array}{l}\text { United } \\
\text { Kingdom }\end{array}$ & $10.0 \%$ & $45.6 \%$ \\
\hline Norway & 0.45 & $13.2 \%$ & $52.5 \%$ & $15.1 \%$ & $19.3 \%$ & USA & $13.6 \%$ & Sweden & $11.8 \%$ & $\begin{array}{l}\text { United } \\
\text { Kingdom }\end{array}$ & $7.1 \%$ & $32.5 \%$ \\
\hline New Zealand & 0.62 & $72.1 \%$ & $6.3 \%$ & $17.3 \%$ & $4.2 \%$ & Australia & $42.3 \%$ & USA & $13.3 \%$ & China & $7.7 \%$ & $63.2 \%$ \\
\hline Portugal & 0.55 & $2.8 \%$ & $59.9 \%$ & $3.3 \%$ & $34.0 \%$ & Spain & $26.5 \%$ & Brazil & $16.6 \%$ & Poland & $12.3 \%$ & $55.4 \%$ \\
\hline Singapore & 0.56 & $69.6 \%$ & $12.7 \%$ & $11.9 \%$ & $5.8 \%$ & China & $16.7 \%$ & Australia & $6.8 \%$ & Malaysia & $5.8 \%$ & $29.3 \%$ \\
\hline Spain & 0.55 & $4.3 \%$ & $50.4 \%$ & $11.4 \%$ & $33.9 \%$ & Portugal & $5.7 \%$ & $\begin{array}{c}\text { United } \\
\text { Kingdom }\end{array}$ & $5.6 \%$ & USA & $4.2 \%$ & $15.5 \%$ \\
\hline Sweden & 0.43 & $7.8 \%$ & $61.5 \%$ & $22.4 \%$ & $8.3 \%$ & USA & $15.8 \%$ & Norway & $5.9 \%$ & Finland & $5.6 \%$ & $27.2 \%$ \\
\hline Switzerland & 0.44 & $11.7 \%$ & $45.7 \%$ & $27.7 \%$ & $14.9 \%$ & Germany & $12.3 \%$ & USA & $11.5 \%$ & France & $10.9 \%$ & $34.6 \%$ \\
\hline $\begin{array}{l}\text { United } \\
\text { Kingdom }\end{array}$ & 0.61 & $11.3 \%$ & $39.8 \%$ & $35.6 \%$ & $13.3 \%$ & USA & $24.7 \%$ & Germany & $9.5 \%$ & France & $6.8 \%$ & $41.0 \%$ \\
\hline United States & 0.58 & $12.6 \%$ & $26.4 \%$ & $57.4 \%$ & $3.6 \%$ & Canada & $10.8 \%$ & $\begin{array}{c}\text { United } \\
\text { Kingdom }\end{array}$ & $3.6 \%$ & Japan & $2.3 \%$ & $16.7 \%$ \\
\hline Average & 0.53 & $20.5 \%$ & $44.2 \%$ & $22.0 \%$ & $13.3 \%$ & & $20.2 \%$ & & $8.8 \%$ & & $5.5 \%$ & $34.4 \%$ \\
\hline
\end{tabular}




\section{Table 2: Univariate Portfolio Sorts}

This table reports the results of value-weighted univariate portfolio sorts. Panel A presents average excess returns (in USD) in month $t$ of five value weighted quintile portfolios sorted on Foreign_Info in month $t-1$. The results are shown for five regions: Global, Global ex US, Asia-Pacific, Europe and North America. Panel A also reports the returns on a self-financing portfolio strategy (5-1) that buys (sells) the top (bottom) quintile portfolio stocks. Panel B reports riskadjused returns for each quintile portfolio and the 5-1 difference portfolio using a regional version of the Carhart (1997) four-factor model. The four risk factors are obtained from Asness et al. (2014). Panel C reports risk-adjusted returns using an international version of the Fama and French (2015a) five-factor model. The risk factors for the five factor model are obtained from the homepage of Kenneth French. We also report the factor loadings of the 5-1 difference portfolio. T-statistics are shown in parentheses and calculated using the Newey and West (1987) method with 12 lags. $*$,** and $* * *$ denote statistical significance at the $10 \%, 5 \%$ and $1 \%$ level, respectively. The sample covers multinational firms from 22 developed markets from June 2001 to December 2013.

Panel A: Portfolio Excess Returns

\begin{tabular}{c|ccccc}
\hline & $(1)$ & $(2)$ & $(3)$ & $(4)$ & $(5)$ \\
\hline & Global & Global ex USA & Asia-Pacific & Europe & North America \\
\hline 1 (low) & 0.15 & 0.32 & 0.19 & 0.49 & 0.20 \\
2 & 0.54 & 0.57 & 0.21 & 0.58 & 0.48 \\
3 & 0.57 & 0.74 & 0.62 & 0.84 & 0.42 \\
4 & 0.64 & 0.68 & 0.76 & 0.79 & 0.74 \\
5 (high) & 1.00 & 0.95 & 1.01 & 0.88 & 1.01 \\
\hline & $0.85^{* * *}$ & $0.63^{* *}$ & $0.81^{* *}$ & 0.38 & $0.81^{* *}$ \\
$5-1$ & $(3.24)$ & $(2.42)$ & $(2.31)$ & $(1.39)$ & $(2.18)$ \\
\hline
\end{tabular}

Panel B: Carhart (1997) Risk-Adjusted Returns

\begin{tabular}{c|ccccc}
\hline & $(1)$ & $(2)$ & $(3)$ & $(4)$ & $(5)$ \\
\hline & Global & Global ex USA & Asia-Pacific & Europe & North America \\
\hline 1 (low) & -0.37 & -0.17 & -0.09 & -0.07 & -0.40 \\
2 & -0.02 & -0.14 & -0.47 & -0.09 & 0.02 \\
3 & 0.07 & 0.08 & -0.01 & 0.07 & 0.01 \\
4 & 0.13 & 0.03 & 0.16 & 0.18 & 0.29 \\
5 (high) & 0.52 & 0.48 & 0.60 & 0.36 & 0.55 \\
\hline $5-1$ & $0.89 * * *$ & $0.65^{* *}$ & $0.69 *$ & 0.43 & $0.94 * *$ \\
& $(3.62)$ & $(2.22)$ & $(1.83)$ & $(1.34)$ & $(2.53)$ \\
MKT & $-0.20^{* * *}$ & $-0.16^{* * *}$ & -0.07 & $-0.18^{* * *}$ & $-0.24 * * *$ \\
& $(-2.99)$ & $(-2.79)$ & $(-1.17)$ & $(-3.14)$ & $(-3.11)$ \\
SMB & $-0.33^{*}$ & $-0.25^{* *}$ & $-0.37 * *$ & -0.14 & -0.19 \\
& $(-1.68)$ & $(-2.18)$ & $(-2.29)$ & $(-1.17)$ & $(-0.84)$ \\
HML & $0.58^{* * *}$ & $0.33^{* *}$ & $0.39 * * *$ & $0.33^{*}$ & $0.39^{* *}$ \\
& $(3.09)$ & $(2.08)$ & $(2.63)$ & $(1.67)$ & $(2.10)$ \\
UMD & $-0.19 *$ & -0.12 & -0.13 & -0.11 & -0.15 \\
& $(-1.77)$ & $(-1.08)$ & $(-1.02)$ & $(-1.22)$ & $(-1.33)$ \\
\hline
\end{tabular}


Panel C: Fama and French (2015) Risk-Adjusted Returns

\begin{tabular}{c|ccccc}
\hline & $(1)$ & $(2)$ & $(3)$ & $(4)$ & $(5)$ \\
\hline 1 (low) & Global & Global ex USA & Asia-Pacific & Europe & North America \\
2 & -0.21 & -0.05 & -0.50 & -0.02 & -0.18 \\
3 & -0.01 & -0.11 & -0.61 & -0.11 & -0.04 \\
4 & -0.02 & 0.06 & -0.22 & 0.04 & -0.06 \\
5 (high) & 0.05 & 0.08 & -0.18 & 0.14 & 0.12 \\
\hline $5-1$ & 0.47 & 0.51 & 0.19 & 0.32 & 0.47 \\
& $0.69 * * *$ & $0.57 * *$ & $0.69 *$ & 0.34 & $0.64 *$ \\
MKT & $(2.86)$ & $(2.51)$ & $(1.94)$ & $(1.47)$ & $(1.79)$ \\
& -0.09 & $-0.13 * *$ & 0.04 & -0.09 & -0.11 \\
SMB & $(-1.54)$ & $(-2.23)$ & $(0.60)$ & $(-1.37)$ & $(-1.21)$ \\
& -0.19 & -0.10 & -0.17 & 0.00 & -0.06 \\
HML & $(-0.99)$ & $(-0.78)$ & $(-1.36)$ & $(0.03)$ & $(-0.26)$ \\
& 0.39 & 0.25 & 0.02 & 0.00 & 0.15 \\
RMW & $(1.50)$ & $(1.33)$ & $(0.24)$ & $(-0.01)$ & $(0.60)$ \\
& 0.18 & 0.21 & 0.14 & 0.16 & 0.12 \\
CMA & $(0.61)$ & $(0.88)$ & $(1.29)$ & $(0.57)$ & $(0.34)$ \\
& 0.18 & -0.06 & 0.02 & 0.15 & 0.46 \\
& $(0.62)$ & $(-0.30)$ & $(0.14)$ & $(0.70)$ & $(1.43)$ \\
\hline
\end{tabular}




\section{Table 3: Fama-MacBeth Regressions}

This table reports the results of Fama and MacBeth (1973) regressions. In specifications (1) - (5), the excess return of multinational firm $i, R_{i, t}$, is regressed on Foreign_Info $o_{i, j, t-1}$ and a vector of control variables. Foreign_Info $o_{i, j, t-1}$ is the sales-weighted foreign industry return of multinational firm $i$ in month $t$-1. Beta is the firm's beta factor, estimated over the previous 60 months. Size is the log market capitalization in USD at the end of previous June. BM is the log book-tomarket ratio in USD at the end of December (in USD). $R_{i, t-12: t-2}$ is the lagged firm return from month t-12 through month $\mathrm{t}-2 . R_{i, t-1}$ is the lagged firm return. Turnover is defined as the number of stocks traded during a given day divided by the number of stocks outstanding at the end of the day, averaged over the past 12 months. Idio_Vola is the standard deviation of the residuals of a market model regression, estimated over the previous 60 months. Dom_Ind_Ret lagged domestic industry return. Dom_Ind_Ret $t_{i,-12: t-2}$ is the lagged domestic industry return from month t-12 through month t-2. Dom_Ind_Ret $t_{i, t}$ is the contemporaneous domestic industry return. Foreign_Info ${ }_{i, j, t}$ is the sales-weighted contemporaneous foreign industry return of multinational firm $i$ in month $t$. In specifications (6) and (7), we use twoand three-month ahead excess returns as dependent variables (instead of one-month ahead excess returns). Specification (8) reports the results of Fama-MacBeth regressions including Foreign_Info_Market ${ }_{i, t-1}$, the sales weighted foreign market return of multinational firm $i$. In specifications (9) and (10) the dependent variable is the risk-adjusted return of multinational firm $i$, where the return is adjusted with respect to the local and geographical sales-weighted Carhart (1997) four factor model, respectively. All returns are denominated in USD. T-statistics are calculated using the Newey and West (1987) method with 12 lags. *** and *** denote statistical significance at the $10 \%, 5 \%$ and $1 \%$ level, respectively. The sample covers multinational firms from 22 developed markets from June 2001 to December 2013. 


\begin{tabular}{|c|c|c|c|c|c|c|c|c|c|c|}
\hline & (1) & (2) & (3) & (4) & (5) & (6) & (7) & (8) & (9) & (10) \\
\hline & Global & $\begin{array}{c}\text { Global ex } \\
\text { USA }\end{array}$ & $\begin{array}{c}\text { Asia- } \\
\text { Pacific }\end{array}$ & Europe & $\begin{array}{c}\text { North } \\
\text { America }\end{array}$ & Global & Global & Global & Global & Global \\
\hline Dependent Variable & $\mathrm{R}_{\mathrm{i}, \mathrm{t}}$ & $\mathrm{R}_{\mathrm{i}, \mathrm{t}}$ & $\mathrm{R}_{\mathrm{i}, \mathrm{t}}$ & $\mathrm{R}_{\mathrm{i}, \mathrm{t}}$ & $\mathrm{R}_{\mathrm{i}, \mathrm{t}}$ & $\mathrm{R}_{\mathrm{i}, \mathrm{t}: \mathrm{t}+1}$ & $\mathrm{R}_{\mathrm{i}, \mathrm{t}: \mathrm{t}+2}$ & $\mathrm{R}_{\mathrm{i}, \mathrm{t}}$ & $\mathrm{R}_{\mathrm{i}, \mathrm{t}}^{\text {adj_local }}$ & $\mathrm{R}_{\mathrm{i}, \mathrm{t}}^{\text {adjgeo }}$ \\
\hline Foreign_Info ${ }_{\mathrm{i}, \mathrm{j}, \mathrm{t}-\mathrm{1}}$ & $\begin{array}{c}0.048 * * * \\
(3.20)\end{array}$ & $\begin{array}{c}0.053^{* * *} * \\
(4.07)\end{array}$ & $\begin{array}{c}0.047 * * \\
(2.54)\end{array}$ & $\begin{array}{c}0.037 * * \\
(2.27)\end{array}$ & $\begin{array}{l}0.044^{*} \\
(1.66)\end{array}$ & $\begin{array}{c}0.073^{* * *} \\
(3.93)\end{array}$ & $\begin{array}{c}0.102 * * * \\
(4.02)\end{array}$ & $\begin{array}{c}0.044 * * * \\
(3.30)\end{array}$ & $\begin{array}{c}0.038^{* * *} \\
(2.67)\end{array}$ & $\begin{array}{l}0.029^{*} \\
(1.73)\end{array}$ \\
\hline Beta & $\begin{array}{l}0.002 \\
(1.16)\end{array}$ & $\begin{array}{l}0.002 \\
(1.24)\end{array}$ & $\begin{array}{l}0.003 \\
(1.28)\end{array}$ & $\begin{array}{l}0.002 \\
(1.24)\end{array}$ & $\begin{array}{l}0.003 \\
(1.50)\end{array}$ & $\begin{array}{l}0.004 \\
(1.15)\end{array}$ & $\begin{array}{l}0.007 \\
(1.17)\end{array}$ & $\begin{array}{l}0.002 \\
(1.17)\end{array}$ & $\begin{array}{l}0.001 \\
(0.63)\end{array}$ & $\begin{array}{l}0.001 \\
(0.59)\end{array}$ \\
\hline Size & $\begin{array}{c}-0.001 * * \\
(-2.21)\end{array}$ & $\begin{array}{l}0.000 \\
(-0.76)\end{array}$ & $\begin{array}{c}-0.001^{* *} \\
(-2.07)\end{array}$ & $\begin{array}{l}0.000 \\
(-0.17)\end{array}$ & $\begin{array}{c}-0.001 * * * \\
(-2.68)\end{array}$ & $\begin{array}{c}-0.002 * * \\
(-2.08)\end{array}$ & $\begin{array}{c}-0.003 * * \\
(-2.05)\end{array}$ & $\begin{array}{c}-0.001 * * \\
(-2.26)\end{array}$ & $\begin{array}{c}0.000 \\
(-0.75)\end{array}$ & $\begin{array}{l}0.000 \\
(-1.13)\end{array}$ \\
\hline $\mathrm{BM}$ & $\begin{array}{c}0.001 * * * \\
(2.85)\end{array}$ & $\begin{array}{c}0.002 * * * \\
(3.89)\end{array}$ & $\begin{array}{c}0.003 * * * \\
(3.77)\end{array}$ & $\begin{array}{l}0.001 \\
(1.48)\end{array}$ & $\begin{array}{l}0.000 \\
(0.24)\end{array}$ & $\begin{array}{c}0.003 * * * \\
(2.87)\end{array}$ & $\begin{array}{c}0.005 * * * \\
(2.78)\end{array}$ & $\begin{array}{c}0.001 * * * \\
(2.80)\end{array}$ & $\begin{array}{l}0.001 \\
(1.35)\end{array}$ & $\begin{array}{l}0.001 \\
(1.35)\end{array}$ \\
\hline $\mathrm{R}_{\mathrm{i}, \mathrm{t}-12: \mathrm{t}-2}$ & $\begin{array}{l}0.002 \\
(0.52)\end{array}$ & $\begin{array}{l}0.005 \\
(1.03)\end{array}$ & $\begin{array}{l}0.002 \\
(0.52)\end{array}$ & $\begin{array}{l}0.008 \\
(1.51)\end{array}$ & $\begin{array}{l}-0.001 \\
(-0.13)\end{array}$ & $\begin{array}{l}0.003 \\
(0.41)\end{array}$ & $\begin{array}{l}0.003 \\
(0.25)\end{array}$ & $\begin{array}{l}0.002 \\
(0.52)\end{array}$ & $\begin{array}{l}0.002 \\
(0.47)\end{array}$ & $\begin{array}{l}0.002 \\
(0.51)\end{array}$ \\
\hline $\mathrm{R}_{\mathrm{i}, \mathrm{t}-1}$ & $\begin{array}{c}-0.013^{* *} \\
(-2.11)\end{array}$ & $\begin{array}{l}-0.009 \\
(-1.35)\end{array}$ & $\begin{array}{l}-0.005 \\
(-0.59)\end{array}$ & $\begin{array}{c}-0.012^{*} \\
(-1.79)\end{array}$ & $\begin{array}{c}-0.018 * * * \\
(-2.66)\end{array}$ & $\begin{array}{l}-0.012 \\
(-1.02)\end{array}$ & $\begin{array}{l}-0.004 \\
(-0.28)\end{array}$ & $\begin{array}{c}-0.012 * * \\
(-2.08)\end{array}$ & $\begin{array}{c}-0.014 * * \\
(-1.99)\end{array}$ & $\begin{array}{l}-0.014^{*} \\
(-1.80)\end{array}$ \\
\hline Turnover & $\begin{array}{c}-0.007 * * * \\
(-3.15)\end{array}$ & $\begin{array}{c}-0.550^{* * *} \\
(-2.72)\end{array}$ & $\begin{array}{c}-0.636^{* * * *} \\
(-3.30)\end{array}$ & $\begin{array}{l}-0.331 \\
(-1.50)\end{array}$ & $\begin{array}{c}-0.006^{* * * *} \\
(-2.63)\end{array}$ & $\begin{array}{c}-0.014 * * * \\
(-3.38)\end{array}$ & $\begin{array}{c}-0.022^{* * *} \\
(-3.44)\end{array}$ & $\begin{array}{c}-0.007 * * * \\
(-3.13)\end{array}$ & $\begin{array}{c}-0.004 * * * \\
(-3.14)\end{array}$ & $\begin{array}{c}-0.006^{* * * *} \\
(-3.41)\end{array}$ \\
\hline Idio_Vola & $\begin{array}{c}-0.005^{* * *} \\
(-3.09)\end{array}$ & $\begin{array}{c}-0.004 * * * \\
(-4.05)\end{array}$ & $\begin{array}{c}-0.006 * * * \\
(-4.91)\end{array}$ & $\begin{array}{c}-0.004 * * \\
(-2.41)\end{array}$ & $\begin{array}{l}-0.003 \\
(-1.29)\end{array}$ & $\begin{array}{c}-0.008^{* * *} \\
(-2.84)\end{array}$ & $\begin{array}{c}-0.012 * * * \\
(-2.78)\end{array}$ & $\begin{array}{c}-0.005^{* * *} \\
(-3.13)\end{array}$ & $\begin{array}{c}-0.003 * * \\
(-2.27)\end{array}$ & $\begin{array}{c}-0.003 * * \\
(-2.10)\end{array}$ \\
\hline Dom_Ind_Ret ${ }_{\mathrm{i}, \mathrm{t}-1}$ & $\begin{array}{c}0.026^{* * * *} \\
(3.83)\end{array}$ & $\begin{array}{c}0.025^{* * *} \\
(3.74)\end{array}$ & $\begin{array}{c}0.040 * * * \\
(3.04)\end{array}$ & $\begin{array}{c}0.017^{* *} \\
(2.00)\end{array}$ & $\begin{array}{c}0.053 * * * \\
(3.55)\end{array}$ & $\begin{array}{c}0.035^{* *} \\
(2.57)\end{array}$ & $\begin{array}{c}0.050^{* * * *} \\
(3.25)\end{array}$ & $\begin{array}{c}0.026^{* * * *} \\
(3.93)\end{array}$ & $\begin{array}{c}0.018^{* * * *} \\
(2.90)\end{array}$ & $\begin{array}{c}0.015^{* *} \\
(2.37)\end{array}$ \\
\hline Dom_Ind_Ret $t_{i, t-12:-1-2}$ & $\begin{array}{l}0.003 \\
(0.77)\end{array}$ & $\begin{array}{l}0.001 \\
(0.26)\end{array}$ & $\begin{array}{l}0.000 \\
(0.11)\end{array}$ & $\begin{array}{l}-0.001 \\
(-0.14)\end{array}$ & $\begin{array}{l}0.008 \\
(1.38)\end{array}$ & $\begin{array}{l}0.007 \\
(1.43)\end{array}$ & $\begin{array}{l}0.014 * \\
(1.71)\end{array}$ & $\begin{array}{l}0.003 \\
(0.73)\end{array}$ & $\begin{array}{l}0.000 \\
(0.06)\end{array}$ & $\begin{array}{l}-0.001 \\
(-0.45)\end{array}$ \\
\hline Dom_Ind_Ret $t_{\mathrm{i}, \mathrm{t}}$ & $\begin{array}{c}0.474 * * * \\
(31.42)\end{array}$ & $\begin{array}{c}0.452 * * * \\
(27.76)\end{array}$ & $\begin{array}{c}0.357 * * * \\
(22.61)\end{array}$ & $\begin{array}{c}0.506 * * * \\
(28.67)\end{array}$ & $\begin{array}{c}0.552 * * * \\
(23.83)\end{array}$ & $\begin{array}{c}0.505^{* * *} \\
(31.91)\end{array}$ & $\begin{array}{c}0.523 * * * \\
(29.59)\end{array}$ & $\begin{array}{c}0.474 * * * \\
(31.53)\end{array}$ & $\begin{array}{c}0.391 * * * \\
(28.69)\end{array}$ & $\begin{array}{c}0.411 * * * \\
(27.15)\end{array}$ \\
\hline $\begin{array}{l}\text { Foreign_Info }{ }_{\mathrm{i}, \mathrm{j}, \mathrm{t}} \\
\text { Foreign_Info_Market }_{\mathrm{i}, \mathrm{j}, \mathrm{t}-1}\end{array}$ & $\begin{array}{c}0.118^{* * * *} \\
(9.72)\end{array}$ & $\begin{array}{c}0.126^{* * *} \\
(9.06)\end{array}$ & $\begin{array}{c}0.091^{* * *} \\
(3.75)\end{array}$ & $\begin{array}{c}0.091 * * * \\
(6.55)\end{array}$ & $\begin{array}{c}0.093 * * * \\
(4.74)\end{array}$ & $\begin{array}{c}0.195^{* * *} \\
(9.78)\end{array}$ & $\begin{array}{c}0.224 * * * \\
(10.91)\end{array}$ & $\begin{array}{c}0.119 * * * \\
(9.31) \\
0.026 \\
(1.17) \\
\end{array}$ & $\begin{array}{c}0.076^{* * *} \\
(6.18)\end{array}$ & $\begin{array}{l}0.014 \\
(0.67)\end{array}$ \\
\hline $\begin{array}{l}\mathrm{N} \\
\mathrm{R} 2 \\
\end{array}$ & $\begin{array}{c}469,742 \\
0.13 \\
\end{array}$ & $\begin{array}{c}325,073 \\
0.16\end{array}$ & $\begin{array}{c}149,501 \\
0.15\end{array}$ & $\begin{array}{c}150,401 \\
0.15\end{array}$ & $\begin{array}{c}169,840 \\
0.08\end{array}$ & $\begin{array}{c}466,021 \\
0.13 \\
\end{array}$ & $\begin{array}{c}462,276 \\
0.13\end{array}$ & $\begin{array}{c}467,798 \\
0.13\end{array}$ & $\begin{array}{c}465,968 \\
0.05\end{array}$ & $\begin{array}{c}453,674 \\
0.06\end{array}$ \\
\hline
\end{tabular}




\section{Table 4: Foreign Information vs. Domestic Industry Momentum}

Panel A presents monthly alphas (in percent) of 25 value weighted quintile portfolios sorted on Dom_Ind_Ret ${ }_{i, t-1}$ and then sorted on Foreign_Info $o_{i, j, t-1}$. The quintile portfolios are constructed by pooling all stocks in the sample, i.e., covering the global region. The alphas are calculated using a global version of the Carhart (1997) four-factor model. The four risk factors are obtained from Asness et al. (2014). All returns are denominated in USD. Panel A also reports the returns on a self-financing portfolio strategy (5-1) that buys (sells) the top (bottom) quintile portfolio. Panel B presents the averages of monthly excess returns of 25 value weighted quintile portfolios sorted on Dom_Ind_Ret Itt-2:t-12 $_{\text {and then }}$ sorted on Foreign_Info ${ }_{i, j, t-1}$. T-statistics are shown in parentheses and calculated using the Newey and West (1987) method with 12 lags. *** and *** denote statistical significance at the $10 \%, 5 \%$ and $1 \%$ level, respectively. The sample covers multinational firms from 22 developed markets from June 2001 to December 2013.

Panel A: Short-term Industry Momentum and Foreign_Info

\begin{tabular}{|c|c|c|c|c|c|c|c|}
\hline & \multicolumn{7}{|c|}{ Dom_Ind_Ret $_{\mathrm{i}, \mathrm{t}-1}$} \\
\hline \multirow{7}{*}{ 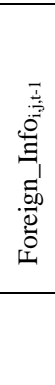 } & & 1 (low) & 2 & 3 & 4 & 5 (high) & Average \\
\hline & 1 (low) & -0.21 & -0.32 & -0.49 & -0.59 & 0.13 & -0.29 \\
\hline & 2 & -0.14 & -0.05 & 0.10 & -0.05 & 0.03 & -0.02 \\
\hline & 3 & -0.23 & -0.03 & 0.26 & 0.02 & 0.25 & 0.05 \\
\hline & 4 & -0.04 & 0.30 & 0.06 & 0.09 & 0.34 & 0.15 \\
\hline & 5 (high) & 0.34 & 0.48 & 0.48 & 0.71 & 0.13 & 0.43 \\
\hline & $5-1$ & $\begin{array}{c}0.55^{* *} \\
(2.05)\end{array}$ & $\begin{array}{c}0.80^{* *} \\
(2.55)\end{array}$ & $\begin{array}{c}0.97 * * * \\
(2.98)\end{array}$ & $\begin{array}{c}1.30 * * * * \\
(3.79)\end{array}$ & $\begin{array}{c}0.00 \\
(0.01)\end{array}$ & 0.72 \\
\hline
\end{tabular}

Panel B: Medium-term Industry Momentum and Foreign_Info

\begin{tabular}{|c|c|c|c|c|c|c|c|}
\hline & \multicolumn{7}{|c|}{ Dom_Ind_Ret $t_{\mathrm{i}, \mathrm{t}-12: \mathrm{t}-2}$} \\
\hline \multirow{7}{*}{ 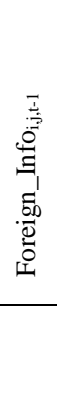 } & & 1 (low) & 2 & 3 & 4 & 5 (high) & Average \\
\hline & 1 (low) & 0.12 & -0.18 & -0.26 & -0.21 & -0.56 & -0.22 \\
\hline & 2 & 0.28 & -0.10 & -0.06 & -0.13 & -0.22 & -0.05 \\
\hline & 3 & 0.90 & 0.00 & 0.13 & -0.09 & 0.13 & 0.22 \\
\hline & 4 & 0.57 & 0.23 & 0.03 & 0.04 & 0.01 & 0.18 \\
\hline & 5 (high) & 0.50 & 0.89 & 0.14 & 0.19 & -0.09 & 0.32 \\
\hline & $5-1$ & $\begin{array}{c}0.37 \\
(1.10)\end{array}$ & $\begin{array}{c}1.07 * * * \\
(3.76)\end{array}$ & $\begin{array}{l}0.40^{*} \\
(1.66)\end{array}$ & $\begin{array}{l}0.39 * \\
(1.84)\end{array}$ & $\begin{array}{l}0.47^{*} \\
(1.80)\end{array}$ & 0.54 \\
\hline
\end{tabular}




\section{Table 5: Robustness}

This table presents robustness checks. We perform univariate portfolio sorts (as in Table 2) on the global sample and adjust excess returns for each quintile portfolio and the 5-1 difference portfolio using a regional version of the Carhart (1997) four-factor model (as in Panel B of Table 2). The four risk factors are obtained from Asness et al. (2014). Column (1) repeats the baseline results of value-weighted portfolio sorts as in column (1) of Panel B in Table 2. Column (2) reports the results when we apply an equal-weighted procedure instead of a value-weighting sorting procedure. Column (3) repeats value-weighted portfolio sorts with adjusted local currency returns. Column (4) reports the results of portfolio sorts when we skip five trading days between the measurement period of Foreign_Inf $o_{i, j, t-1}$ and the start of the portfolio formation period. In column (5), we repeat the portfolio sorts using only the $20 \%$ largest firms in each country and month. Column (6) shows portfolio sort results excluding all firms from our sample that operate in the financial sector. In column (7), we present portfolio sort results excluding firms with a total share of foreign sales less than $20 \%$ to ensure that our results are not driven by firms with a negligible fraction of foreign sales. Column (8), we present portfolio sort results excluding all multinational firms with foreign sales in emerging markets. Finally, in column (9) we exclude all firms from the sample that do not exclusively report individual countries in all geographic segments. T-statistics are calculated using the Newey and West (1987) method with 12 lags. $* * *$ and $* * *$ denote statistical significance at the $10 \%, 5 \%$ and $1 \%$ level, respectively. The sample covers multinational firms from 22 developed markets from June 2001 to December 2013

\begin{tabular}{|c|c|c|c|c|c|c|c|c|c|}
\hline & (1) & (2) & (3) & (4) & (5) & (6) & (7) & (8) & (9) \\
\hline & Baseline & $\begin{array}{c}\text { Equal- } \\
\text { Weighted }\end{array}$ & $\begin{array}{c}\text { Local } \\
\text { Currency }\end{array}$ & $\begin{array}{l}5 \text { Trading } \\
\text { Days Skip }\end{array}$ & $\begin{array}{c}20 \% \text { Largest } \\
\text { Firms }\end{array}$ & $\begin{array}{l}\text { Excluding } \\
\text { Financials }\end{array}$ & $\begin{array}{c}\text { Exclude } \\
\text { Foreign } \\
\text { Sales Share } \\
<20 \%\end{array}$ & $\begin{array}{c}\text { Exclude } \\
\text { Foreign } \\
\text { Sales in } \\
\text { Emerging } \\
\text { Markets }\end{array}$ & $\begin{array}{c}\text { Firms only } \\
\text { Reporting } \\
\text { Individual } \\
\text { Country } \\
\text { Segments }\end{array}$ \\
\hline 1 (low) & -0.37 & -0.28 & -0.32 & -0.40 & -0.37 & -0.35 & -0.31 & -0.28 & -0.24 \\
\hline 2 & -0.02 & 0.02 & -0.02 & -0.11 & -0.01 & 0.06 & -0.09 & 0.14 & -0.20 \\
\hline 3 & 0.07 & 0.23 & 0.07 & 0.04 & -0.01 & 0.09 & 0.11 & 0.04 & 0.16 \\
\hline 4 & 0.13 & 0.43 & 0.09 & 0.04 & 0.22 & 0.25 & 0.21 & 0.28 & 0.25 \\
\hline 5 (high) & 0.52 & 0.70 & 0.43 & 0.42 & 0.49 & 0.62 & 0.60 & 0.55 & 0.41 \\
\hline $5-1$ & $\begin{array}{c}0.89 * * * \\
(3.62)\end{array}$ & $\begin{array}{c}0.98 * * * \\
(3.48) \\
\end{array}$ & $\begin{array}{c}0.75^{* * * *} \\
(3.13) \\
\end{array}$ & $\begin{array}{c}0.82 * * * \\
(3.42) \\
\end{array}$ & $\begin{array}{c}0.86^{* * * *} \\
(3.75) \\
\end{array}$ & $\begin{array}{c}0.97 * * * \\
(3.70) \\
\end{array}$ & $\begin{array}{c}0.91 * * * \\
(3.11) \\
\end{array}$ & $\begin{array}{c}0.83^{* * * *} \\
(2.91) \\
\end{array}$ & $\begin{array}{l}0.65 * * \\
(2.54) \\
\end{array}$ \\
\hline
\end{tabular}




\section{Table 6: Comovement of Individual Country Portfolio Returns}

Panel A of this table presents the results of univariate portfolio sorts, factor models, and correlation coefficients for individual country portfolio returns. Columns (1) - (4) present the averages of monthly returns (in \%) of value-weighted top and bottom tercile portfolios sorted on Foreign Info in month $t$ - 1 for each individual country together with the returns and t-statistics of a self-financing portfolio strategy (3-1) that buys (sells) the top (bottom) tercile portfolio. All returns are denominated in USD. Columns (5) - (6) report the alpha with t-statistics of a Carhart (1997) four factor model, where the 3-1 returns of each country are regressed on corresponding country-specific risk factors. The risk factors are obtained from Asness et al. (2014). In columns (7) and (8), we display the average correlation of a country's long-short (3-1) portfolio strategy with all other long-short (3-1) portfolio strategies in the sample. Finally, in columns (9) (13), we report the results of a time-series regression of the country-specific long-short (3-1) portfolio strategy on the global (3-1) portfolio strategy including the coefficient estimate (with t-statistics) of the global portfolio, the regression alpha (with t-statistics) and the R2 of the regression. Panel B reports the Eigenvalue, as well as individual and cumulative variance explained by the first ten principal components of the matrix of country-specific High - Low Foreign_Info return spreads. T-statistics are calculated using the Newey and West (1987) method with 12 lags. *** and *** denote statistical significance at the 10\%, 5\% and 1\% level, respectively. The sample covers multinational firms from 22 developed markets from June 2001 to December 2013.

Panel A: Individual Portfolio Sorts, Factor Models, and Correlation Coefficients

\begin{tabular}{|c|c|c|c|c|c|c|c|c|c|c|c|c|}
\hline & (1) & (2) & (3) & (4) & (5) & (6) & (7) & (8) & (9) & (10) & $(11)$ & (12) \\
\hline & & Return (in\%) & & & Four-Fac & Alpha & Correlation & & & Factor M & & \\
\hline & Low Foreign_Info & High Foreign_Info & High - Low & t-stat & High - Low & t-stat & Average & Beta & t-stat & Alpha & t-stat & R2 \\
\hline Australia & 1.03 & 1.29 & 0.27 & $(0.82)$ & 0.33 & $(1.04)$ & 0.11 & 0.25 & $(1.39)$ & 0.12 & $(0.34)$ & 0.03 \\
\hline Austria & 1.36 & 1.84 & 0.48 & $(1.16)$ & 0.79 & $(1.53)$ & 0.07 & 0.26 & $(0.73)$ & 0.25 & $(0.44)$ & 0.01 \\
\hline Belgium & 0.20 & 1.32 & $1.12 * *$ & $(2.07)$ & $1.41 * *$ & $(2.21)$ & 0.08 & 0.22 & $(0.69)$ & $1.00 *$ & $(1.88)$ & 0.01 \\
\hline Canada & 0.96 & 1.03 & 0.07 & $(0.15)$ & 0.33 & $(0.21)$ & 0.15 & $0.70 * * *$ & $(6.15)$ & 0.07 & $(0.43)$ & 0.15 \\
\hline Denmark & 0.30 & 1.64 & $1.34 * *$ & $(2.19)$ & $1.31 *$ & $(1.71)$ & 0.11 & $0.57 * * *$ & (3.79) & $0.99 * *$ & $(2.06)$ & 0.05 \\
\hline Finland & 1.24 & 1.03 & -0.22 & $(-0.33)$ & -0.17 & $(-0.23)$ & 0.07 & 0.31 & $(0.70)$ & -0.16 & $(-0.25)$ & 0.01 \\
\hline France & 0.53 & 0.83 & 0.30 & $(0.91)$ & 0.21 & $(0.47)$ & 0.20 & $0.79 * * *$ & $(4.60)$ & -0.21 & $(-0.65)$ & 0.29 \\
\hline Germany & 0.69 & 0.88 & 0.19 & $(0.73)$ & 0.12 & $(0.69)$ & 0.16 & $0.49 * * *$ & $(4.67)$ & 0.07 & $(0.06)$ & 0.12 \\
\hline Hong Kong & 0.47 & 1.43 & $0.96 * * *$ & $(2.81)$ & $0.66^{*}$ & $(1.70)$ & 0.08 & $0.38 * * *$ & $(3.30)$ & $0.82 * *$ & $(1.98)$ & 0.04 \\
\hline Ireland & -0.18 & 1.58 & 1.76 & $(1.55)$ & 0.98 & $(0.92)$ & 0.10 & $1.21 * * *$ & $(2.80)$ & $1.34^{*}$ & $(1.75)$ & 0.05 \\
\hline Italy & 0.39 & 0.44 & 0.05 & $(0.18)$ & 0.26 & $(0.96)$ & 0.16 & $0.55^{* * *}$ & (3.43) & -0.33 & $(-1.00)$ & 0.12 \\
\hline Japan & -0.18 & 0.60 & $0.78 * * *$ & $(4.03)$ & $0.72 * *$ & $(2.45)$ & 0.14 & $0.39 * * *$ & $(6.26)$ & 0.59 *** & $(3.59)$ & 0.11 \\
\hline Netherlands & 0.58 & 1.08 & $0.50 *$ & (1.84) & $0.59 *$ & (1.73) & 0.19 & $0.84 * * *$ & (3.03) & 0.01 & $(0.04)$ & 0.15 \\
\hline Norway & 1.08 & 1.51 & 0.43 & $(0.75)$ & $0.91 *$ & (1.78) & 0.08 & 0.29 & $(0.74)$ & 0.08 & $(0.16)$ & 0.01 \\
\hline New Zealand & 1.09 & 1.39 & 0.30 & $(0.52)$ & 0.12 & $(0.24)$ & -0.06 & $-0.32 * * *$ & $(-2.73)$ & $0.59 *$ & $(1.72)$ & 0.02 \\
\hline Portugal & 0.37 & 0.40 & 0.03 & $(-0.04)$ & -0.18 & $(-0.21)$ & 0.06 & 0.32 & $(1.25)$ & -0.17 & $(-0.26)$ & 0.01 \\
\hline Singapore & 0.50 & 1.75 & $1.25 * * *$ & $(4.02)$ & $1.19 * * *$ & $(3.72)$ & 0.08 & $0.49 * * *$ & $(3.61)$ & $0.98 * * *$ & $(3.87)$ & 0.09 \\
\hline Spain & 0.73 & 0.87 & 0.15 & $(0.43)$ & 0.22 & $(0.63)$ & 0.14 & $0.60 * * *$ & $(3.30)$ & 0.16 & $(0.92)$ & 0.13 \\
\hline Sweden & 0.98 & 1.13 & 0.16 & $(0.48)$ & $0.70 * *$ & $(2.32)$ & 0.11 & $0.36^{* *}$ & $(2.54)$ & 0.06 & $(0.17)$ & 0.03 \\
\hline Switzerland & 0.24 & 1.37 & $1.13 * * *$ & $(3.15)$ & $1.31 * * *$ & (3.79) & 0.21 & $1.19 * * *$ & (7.74) & $0.56^{*}$ & (1.74) & 0.31 \\
\hline UK & 0.30 & 0.87 & 0.56 *** & $(2.82)$ & $0.74 * *$ & $(2.48)$ & 0.17 & $0.65 * * *$ & $(5.41)$ & $0.38^{*}$ & $(1.70)$ & 0.21 \\
\hline USA & 0.27 & 0.79 & $0.52 * *$ & $(2.02)$ & $0.53 * *$ & $(2.38)$ & 0.23 & $0.68 * * *$ & $(4.90)$ & 0.15 & $(0.68)$ & 0.27 \\
\hline Average & 0.59 & 1.14 & 0.55 & - & 0.59 & - & 0.12 & 0.51 & - & 0.33 & - & 0.10 \\
\hline
\end{tabular}


Panel B: Principal Component Analysis

\begin{tabular}{cccc}
\hline & $(1)$ & $(2)$ & $(3)$ \\
\hline Principal Component & Eigenvalue & Individual Variance Explained & Cumulative Variance Explained \\
\hline PC1 & 4.23 & 0.192 & 0.192 \\
PC2 & 1.72 & 0.078 & 0.270 \\
PC3 & 1.51 & 0.069 & 0.339 \\
PC4 & 1.44 & 0.066 & 0.405 \\
PC5 & 1.27 & 0.058 & 0.463 \\
PC6 & 1.21 & 0.055 & 0.518 \\
PC7 & 1.13 & 0.051 & 0.569 \\
PC8 & 1.02 & 0.047 & 0.616 \\
PC9 & 0.96 & 0.044 & 0.660 \\
PC10 & 0.92 & 0.042 & 0.702 \\
\hline
\end{tabular}




\section{Table 7: Drivers of the Foreign Information Effect: Firm Characteristics}

This table reports the estimated coefficients and t-statistics (in parentheses) of Fama-MacBeth (1973) regressions with interaction terms between Foreign_Info ${ }_{i, j, t-1}$ and various proxy variables for firm level investor attention. The excess return of multinational firm $i, R_{i, t}$, is regressed on Foreign_Info ${ }_{i, j, t-1}$, a vector of control variables, a dummy variable which is equal to one if the attention proxy of multinational $i$ in the previous month is above the cross-sectional median of all firms, and the interaction term between Foreign_Info ${ }_{i, j, t-1}$ and the dummy variable. We report the coefficient estimate of the interaction terms. All regressions also include the standard set of control variables as described in the text. Foreign_Info $o_{i, j, t-1}$ is the sales weighted foreign industry return of multinational firm $i$ in month t-1. Size is the log market capitalization in USD at the end of June. Res_Num_Ana is the residual number of equity analysts providing earnings forecasts for a firm, orthogonalized with respect to firm size following Hong et al. (2000). Res_Ownership is the residual percentage of shares outstanding held by institutional investors, orthogonalized with respect to firm size. Res_Num Investors is the residual number of individual institutional investors owning shares of a firm, orthogonalized with respect to size. Idio_Vola is the firm's idiosyncratic volatility. Geographical_Distance is the sales-weighted geographical distance between the resident country of a multinational firm and its respective foreign geographical segments. Cultural_Distance is the distance measure based on the six cultural dimensions of Hofstede et al. (2010). Sales_Same_Language is the firm's share of sales from foreign countries with the same official language as the firm's resident country. T-statistics are calculated using the Newey and West (1987) method with 12 lags. *** and *** denote statistical significance at the $10 \%, 5 \%$ and $1 \%$ level, respectively. The sample covers multinational firms from 22 developed markets from June 2001 to December 2013.

\begin{tabular}{|c|c|c|c|c|c|c|c|c|}
\hline & (1) & (2) & (3) & (4) & (5) & (6) & (7) & (8) \\
\hline Size $>$ Median & $\begin{array}{c}-0.05 * * \\
(-2.25)\end{array}$ & & & & & & & \\
\hline Res_Num_Ana > Median & & $\begin{array}{c}-0.05 * * \\
(-2.14)\end{array}$ & & & & & & \\
\hline Res_Ownership > Median & & & $\begin{array}{c}-0.01 \\
(-0.32)\end{array}$ & & & & & \\
\hline Res_Num_Investors > Median & & & & $\begin{array}{l}-0.04^{*} \\
(-1.91)\end{array}$ & & & & \\
\hline Idio_Vola > Median & & & & & $\begin{array}{c}0.06 * * * * \\
(3.07)\end{array}$ & & & \\
\hline Geographical_Distance > Median & & & & & & $\begin{array}{l}-0.02 \\
(-0.74)\end{array}$ & & \\
\hline Cultural_Distance $>$ Median & & & & & & & $\begin{array}{c}-0.06 \\
(-0.60)\end{array}$ & \\
\hline Sales_Same_Language $>$ Median & & & & & & & & $\begin{array}{l}-0.02^{*} \\
(-1.84) \\
\end{array}$ \\
\hline Standard Controls & Yes & Yes & Yes & Yes & Yes & Yes & Yes & Yes \\
\hline $\mathrm{N}$ & 469742 & 469742 & 305402 & 344786 & 469742 & 469742 & 469742 & 469742 \\
\hline $\mathrm{R} 2$ & 0.13 & 0.13 & 0.16 & 0.12 & 0.13 & 0.13 & 0.13 & 0.14 \\
\hline
\end{tabular}




\section{Table 8: Drivers of the Foreign Information Effect: Time-Series Variation}

This table reports the results of OLS-regressions of country $c^{\prime}$ s Foreign_Info return spread in month $t$ on country $c$ 's measures of investor attention in month $t-1 . R_{c, t}^{L S}$ denotes country $c$ 's Foreign_Info return spread in month $t, A S V I_{c, t-1}$ denotes one of the abnormal attention measure of individuals in country $c$ in month $t$ - 1 . We also control for different country characteristics (Size, Num_Analyst, Ownership, Num_Investors, as defined in Section 5.1) measured at month $t$ 1 , as well as the local market return and market volatility (computed as the past 36 months rolling standard deviation of the market return) at month $t$. We perform the OLS regression including country-fixed effects and Newey-West standard errors. In column (1), we use abnormal overall attention as our only independent variable. We separate overall attention into domestic and foreign attention in column (2). T-statistics are calculated using the Newey and West (1987) method with 12 lags. $* * *$ and $* * *$ denote statistical significance at the $10 \%, 5 \%$ and $1 \%$ level, respectively. The sample covers multinational firms from 22 developed markets from 2004 to 2013.

\begin{tabular}{lcc}
\hline & $(1)$ & $(2)$ \\
& $R_{c, t}^{L S}$ & $R_{c, t}^{L S}$ \\
\hline Overall_ASVI & -0.00555 & \\
& $(-1.04)$ & \\
Domestic_ASVI & & 0.00124 \\
& & $(0.26)$ \\
Foreign_ASVI & & $-0.00934^{* *}, t-1$ \\
& & $(-2.19)$ \\
Additional Controls & & \\
Constant & Yes & Yes \\
& 0.00724 & 0.00651 \\
$\mathrm{~N}$ & $(1.58)$ & $(1.41)$ \\
$\mathrm{R} 2$ & 2,595 & 2,595 \\
\hline
\end{tabular}




\section{Table 9: Drivers of the Foreign Information Effect: Country Characteristics}

In Panel A of this table we regress country c's monthly Foreign_Info return spread in month $t$ on time-fixed country characteristics controlling for different time-varying variables (such as Size, Num_Analyst, Ownership, Num_Investors, as defined in Section 5.1) measured in month $t$ - 1 , as well as the local market return and market volatility (computed as the past 36 months rolling standard deviation of the market return) in month $t$. We use a pooled regression framework with Newey-West standard errors. As explanatory variables we use both investor characteristics and macroeconomic variables. As investor characteristics we include a country's Domestic Bias, Foreign Bias, the average years of schooling of a country's resident (Schooling), and a country's Trust level. Included macroeconomic variables are a country's equity market segmentation (Segmentation), capital flow resrictions (Capital Flow Restrictions), a country's credit rating (Credit Rating) as well as stock market turnover (Turnover) and trading volume (Trading). In Panel B, we perform the same regressions as in Panel A, but use the high minus low post-earnings-announcement-drift following earnings surprises of a country $c$ 's purely domestic stocks $\left(P E A D_{c, t}\right)$ as the dependent variable. T-statistics are shown in parentheses and calculated using the Newey and West (1987) method with 12 lags. *** and *** denote statistical significance at the $10 \%, 5 \%$ and $1 \%$ level, respectively. The sample covers multinational firms from 22 developed markets from June 2001 to December 2013.

Panel A: Determinants of the Foreign_Info Return Spread

\begin{tabular}{lcc}
\hline & $(1)$ & $(2)$ \\
& Investor Characteristics & Macroeconomic \\
& $R_{c, t}^{L S}$ & Variables \\
& $0.00488^{*}$ & $R_{c, t}^{L S}$ \\
\hline Domestic Bias & $(1.72)$ & \\
Foreign Bias & 0.00165 & \\
& $(1.22)$ & \\
Schooling & 0.00110 & \\
& $(0.66)$ & \\
Trust & -0.0145 & \\
& $(-0.74)$ & $0.00321^{*}$ \\
Segmentation & & $(1.75)$ \\
& & 0.00204 \\
Capital Flow Restrictions & & $(1.09)$ \\
& & -0.000218 \\
Credit Rating & & $(-0.50)$ \\
& & -0.000132 \\
Turnover & & $(-1.39)$ \\
& & 0.0000249 \\
Trading & & $(0.05)$ \\
& & Yes \\
Additional Controls & Yes & -0.00427 \\
Constant & 0.0130 & $(-0.12)$ \\
& $(0.94)$ & 2,418 \\
$\mathrm{~N}$ R2 & 2,304 & 0.011 \\
\hline
\end{tabular}


Panel B: Determinants of the Post-Earning-Announcement-Drifts of a Country's Domestic Stocks

\begin{tabular}{lcc}
\hline & $(1)$ & $(2)$ \\
& Investor Characteristics & Macroeconomic \\
& Variables & \\
& $P E A D_{c, t}$ - Domestic & $P E A D_{c, t}-$ Domestic \\
& Stocks Only & Stocks Only \\
\hline Domestic Bias & 0.00165 & \\
Foreign Bias & $(0.50)$ & \\
& $0.0177^{*}$ & \\
Schooling & $(1.71)$ & \\
& 0.0868 & \\
Trust & $(1.39)$ & \\
& -0.0772 & \\
Segmentation & $(-0.93)$ & 0.00597 \\
& & $(0.82)$ \\
Capital Flow Restrictions & & -0.00642 \\
& & $(-1.39)$ \\
Credit Rating & & -0.000498 \\
& & $(-0.34)$ \\
Turnover & & -0.000209 \\
& & $(-0.61)$ \\
Trading & & 0.000169 \\
& & $(0.96)$ \\
Additional Controls & & Yes \\
Constant & Yes & 0.116 \\
& 0.0537 & $(0.94)$ \\
\hline N 2 & $(0.75)$ & 2,418 \\
& 2.292 & 0.009 \\
\hline
\end{tabular}

